\title{
Evaluation of AMSR-E retrieval by detecting soil moisture decrease following massive dryland re-vegetation in the Loess Plateau, China
}

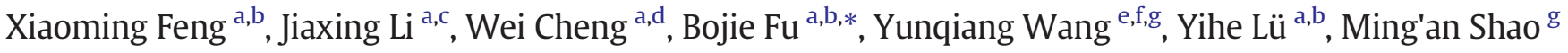 \\ a State Key Laboratory of Urban and Regional Ecology, Research Center for Eco-Environmental Sciences, Chinese Academy of Sciences, Beijing 100085, China \\ ${ }^{\mathrm{b}}$ Joint Center for Global Change Studies, Beijing 100875, China \\ c University of Chinese Academy of Sciences, Beijing 100049, China \\ d School of Life Science, University of Science and Technology of China, Hefei, Anhui 230026, China \\ e State Key Laboratory of Loess and Quaternary Geology, Institute of Earth Environment, Chinese Academy of Sciences, Xi'an, Shaanxi 710061, China

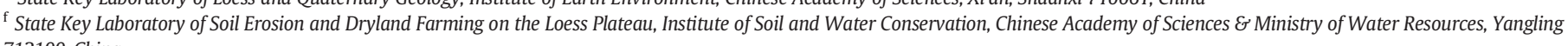 \\ 712100, China \\ ${ }^{\mathrm{g}}$ Key Laboratory of Ecosystem Network Observation and Modeling, Institute of Geographic Sciences and Natural Resources Research, Chinese Academy of Sciences, Beijing 100101, China
}

\section{A R T I C L E I N F O}

Article history:

Received 31 August 2016

Received in revised form 16 April 2017

Accepted 12 May 2017

Available online 19 May 2017

\section{Keywords:}

AMSR-E

Loess Plateau

Precipitation gradient

Re-vegetation

Soil moisture

\begin{abstract}
A B S T R A C T
Knowledge of soil moisture, however varied in space and time, is critical for planning land use in water-limited drylands. Although satellite observations provide soil moisture instantaneously at large scale, few studies have addressed the application of satellite soil moisture retrieval in dryland areas with changing land use. In this study, we propose a method to evaluate the spatiotemporal variance of satellite retrieval based on the evaluation of soil moisture retrievals from the Advanced Microwave Scanning Radiometer on the Earth Observing System (AMSR-E). The operation period of this instrument (June 2002 to October 2011) covers the re-vegetation of the semi-arid Loess Plateau. Our study found that AMSR-E retrievals posted by the Japanese Aerospace Exploration Agency (JAXA) capture the spatiotemporal variance of soil moisture in the Loess Plateau, as well as the in-situ measured soil moisture decrease following the massive re-vegetation- despite it differing from the in-situ measurement in spatial scale. Soil moisture decrease in response to the massive re-vegetation occurred in a transition zone of grass-forest ecosystems with annual precipitation between 450 and $550 \mathrm{~mm}$. Our study suggests that current AMSR-E JAXA retrievals are an essential alternative to field measurement and model simulation, because they can identify the location and spatial extent of areas where soil moisture is sensitive to climate change and managed re-vegetation. To avoid the overconsumption of soil water and limited plant growth in transition zone, managers of dryland areas should pay special attention to species selection.
\end{abstract}

(c) 2017 Elsevier Inc. All rights reserved.

\section{Introduction}

Soil moisture (SM) plays a central role in the functioning of ecosystems. It constrains plant transpiration and photosynthesis, yet supports vegetation growth (see Seneviratne et al., 2010). However, SM is highly heterogeneous, both in space and in time. This heterogeneity reflects variability in rainfall distribution, land use, and irrigation, as well as in soil physical properties, topography and so on (Hawley et al., 1983;Western and Blöschl, 1999; Rosnay et al., 2006; Sun et al., 2014). Understanding the spatiotemporal variance in SM is important if we are to develop sustainable management systems for the maintenance and development of dryland ecosystems (Peng et al., 2015).

\footnotetext{
* Corresponding author at: State Key Lab. of Urban and Regional Ecology, Research Centre for Eco-Environmental Sciences, Chinese Academy of Sciences, PO Box 2871, Beijing 100085, China.

E-mail address: bfu@rcees.ac.cn (B. Fu).
}

Worldwide, drylands support 30\% of the world's population (Menz et al., 2013), and management interventions, such as re-vegetation of dryland, provide landscape-scale opportunities for enhancing the ecosystem services delivered by these drylands (e.g., carbon sequestration, soil retention, etc) (Lal, 2001, 2004). Dryland re-vegetation programs have been implemented extensively over the past century (Del Lungo et al., 2006; IPCC, 2014) and these have brought pronounced changes to SM. Re-vegetation changes the effect of precipitation on SM (Vivoni et al., 2008): it increases transpiration, increases canopy rainfall interception and evaporation, but, by shading the soil surface, decreases evaporation from the soil (Bublinec, 1971). The magnitude and sign of the influences of vegetation cover on SM, vary from place to place depending on the climate (Chen et al., 2009), as well as on the species planted (Aranda et al., 2012; Jost et al., 2012) and the age of plantation (Deng et al., 2016). The planting of unsuitable vegetation in drylands may cause the severe depletion of SM due to overconsumption of the limited precipitation input (Chen et al., 2007; Sanchez-Mejia et al., 2014; Deng et al., 2016). It is therefore essential that the spatial and 
temporal variation in SM is monitored following re-vegetation, so that the suitability of the species being used can be assessed (Ivanov et al., 2010; Yang et al., 2015).

Field measurements give an instantaneous picture of SM, but are time-consuming if a large region is to be covered. On the other hand, satellites can monitor the Earth's surface at large scale (H. Wang et al., 2010; Y. Q. Wang et al., 2010). Over the past two decades, great efforts have been made to develop soil moisture products from satellite observations, including Nimbus Scanning Multi-channel Microwave Radiometer (SMMR; Wang, 1985), Special Sensor Microwave/Imager (SSM/I; De Ridder, 2003), Tropical Rainfall Measuring Mission's (TRMM, Bindlish et al., 2003), Advanced Microwave Scanning Radiometer on the Earth Observing System (AMSR-E; Njoku and Li, 1999), Advanced Microwave ScanningRadiometer-2 (AMSR-2; Imaoka et al., 2010) and the Advanced Scatterometer (ASCAT; Wagner et al., 2013). In particular, after 2009, specifically dedicated Soil Moisture and Ocean Salinity missions (SMOS; Kerr et al., 2010) and the Soil Moisture Active Passive (SMAP, Entekhabi et al., 2010) mission were launched, aiming at routine soil moisture estimation at the optimum frequency band (L-band) for SM monitoring. To understand the performance of satellite observations at the global scale, model simulations were used as the independent reference (e.g., Dorigo et al., 2010; Al-Yaari et al., 2014a, 2014b). For evaluations in different regions of the world, the scale mismatch between the satellite footprint and the representative area captured by a single station has led to the evaluations of satellite retrievals being carried out using networks of in-situ moisture measurements (Albergel et al., 2012; Al Bitar et al., 2012;Draper et al., 2009; Qin et al., 2013). Satellite retrievals are also evaluated by comparison to ancillary spatial data (i.e., land use, saturated water content (Cheema et al., 2011), rainfall (Tuttle and Salvucci, 2014) or model simulation (Rötzer et al., 2014), in areas where it would not be technically feasible to install a network of in-situ moisture measurements. As for the error metrics applied in the evaluation, high absolute errors (i.e., bias; root mean squared error, RMSE) arise from the scale mismatch of point-scale measurements and coarse-scale satellite data. With the acceptance that higher RMSE does not necessarily mean larger absolute errors in satellite data, but rather a mismatch in measurement scale, many studies report unbiased RMSE (Entekhabi et al., 2009), decomposed RMSE (Su et al., 2013) and their multi-temporal evaluation (Su et al., 2016). Great emphasis was also put on correlation metrics and the use of triple collocation analysis (Miralles et al., 2010; Gruber et al., 2013, 2016). Current evaluation shows the improved performance of satellite-measured SM with the launch of new dedicated missions, as well as the evolution of retrieval algorithms. It was demonstrated that, when compared to other satellite products (i.e., ASCAT, AMSR-E, AMSR-2, SMAP), SMOS achieves its expected goals: i) to obtain surface soil moisture fields that fulfill the requirements of an accuracy of $\pm 0.04 \mathrm{~m}^{3} \mathrm{~m}^{-3}$ over non-forested areas of medium to low topography without snow or frozen soils at least twice in $<3$ days, and ii) is globally consistent over different eco-climatic regions from low to high latitudes and throughout the seasons (Kerr et al., 2016). It has also been found that the current beta-quality version of the SMAP SM product agrees well with the insitu measurements from SM networks in the US, Finland, Romania and Canada, the unbiased RMSE being well within the mission requirement of $0.04 \mathrm{~m}^{3} \mathrm{~m}^{-3}$ (Adams et al., 2015; Zeng et al., 2016). It is worth noting that all passive-based soil moisture retrieval approaches screen for unfavorable ground conditions and do not carry out retrieval when these occur; this includes mountainous areas where the presence of dense forested vegetation may cause strong attenuation of the microwave signal (Jackson et al., 1982; Mialon et al., 2008) or exposed rocks which create conversion problems with the dielectric mixing model (Al-Yaari et al., 2014b). The available global soil moisture retrievals do not meet the mission-specified accuracy over certain areas. Zeng et al. (2015) declared that the AMSR-E and AMSR2 products underestimate the ground measurements in the Tibetan Plateau area most of the time (RMSE exceeding $0.09 \mathrm{~m}^{3} \mathrm{~m}^{-3}$ ). Escorihuela and Quintana-Seguí
(2016) found that for Mediterranean landscapes, SMOS has difficulties in areas close to the sea and in areas with steep relief, and ASCAT shows some limitations over agricultural land and natural vegetation, where it shows an increase of soil moisture from June to October probably due to increase of root penetration depth in dry soil moisture conditions. Critical evaluation remains essential before the application of satellite SM retrieval in regional analysis. However, in places without an accurate network of representative monitoring, sites, evaluating the quality of SM retrieval remains problematic (Famiglietti et al., 1999; Kerr et al., 2016). Furthermore, the applicability of satellitederived SM to capturing soil moisture change is not currently under evaluation. Thus for dryland areas with changing land use, it remains unclear if and how the current satellite retrievals will benefit the analysis of changes in SM following land-use change.

Beginning in 2000, the water-limited Loess Plateau in northern China has been subject to massive re-vegetation. The overall purpose of this change was to reduce the serious soil erosion. Arable lands on steep $\left(>25^{\circ}\right)$ slopes have been converted into woodland, shrubland or grasslands (Liu et al., 2008; Fu et al., 2011; Chen et al., 2015), with vegetation coverage increasing from 31.6\% in 1999 to $59.6 \%$ in 2013 (Chen et al., 2015). The re-vegetation in the Loess Plateau has provided some ecological benefits such as carbon sequestration, soil and water conservation, and increased ecosystem productivity (Lü et al., 2012); however, it has also altered the SM (Feng et al., 2016; Wang et al., 2016). The species planted, for example Popul ustremula and Salix psammophila, grow rapidly, but at the cost of a greater water use than native species (Liu et al., 2008; Cao et al., 2011). Moreover, the high density of planted vegetation intensified the excessive demand for soil moisture in the 2000s, which was a period of stable precipitation and temperature (X. M. Feng et al., 2013; Q. Feng et al., 2013; Yang et al., 2014). Since the implementation of re-vegetation in 2000 , this unsustainable water demand has caused soil desiccation, which in turn has resulted in the mortality of the planted vegetation (Cao, 2008; Cao et al., 2011; Feng et al., 2012). Thus, understanding of the soil moisture change is essential for the sustainability of re-vegetation in the Loess Plateau. Current knowledge of SM change in the Loess Plateau is based on in-situ measurements in sample plots or within small catchments (areas varying from $2 \mathrm{~km}^{2}$ to $10 \mathrm{~km}^{2}$ ), these both demonstrate the decrease in SM after the revegetation (Chen et al., 2010; Yang et al., 2014). However, because the sampling plots were concentrated in the most highly re-vegetated areas, we lack a general picture of SM change over the entire Loess Plateau.

The objectives of our study were: 1 ) to evaluate the ability of satellite SM retrievals to capture the spatiotemporal variance of SM over the Loess Plateau; and 2) to use satellite SM retrievals to detect the spatial variability of SM change following the massive re-vegetation of this area. AMSR-E retrievals were selected because they use one of the first sensors to target SM as a standard product, and AMSR-E products have previously shown encouraging results in semi-arid regions with sparse vegetation (Brocca et al., 2011; Su et al., 2013; Al-Yaari et al., 2014a; Tuttle and Salvucci, 2014). Critically, the operation period of AMSR-E, i.e., between June 2002 and October2011, also covers the period of intensive planting in the Loess Plateau.

\section{Study area and data}

\subsection{Study area}

The Loess Plateau in northern China is located in the catchment of the middle reaches of the Yellow River; it covers an area of $640,000 \mathrm{~km}^{2}$ (Fig. 1a). The average annual precipitation varies from $750 \mathrm{~mm}$ in the southeast, to $200 \mathrm{~mm}$ in the northwest, with $>70 \%$ in the growing season between May and September; average annual temperature ranges from $14.3^{\circ} \mathrm{C}$ to $4.3^{\circ} \mathrm{C}$ during the study period of 2003 2011; the bio-climatic classification ranges from semi-humid forest, semi-humid to semi-arid forest-grasslands, semi-arid typical 

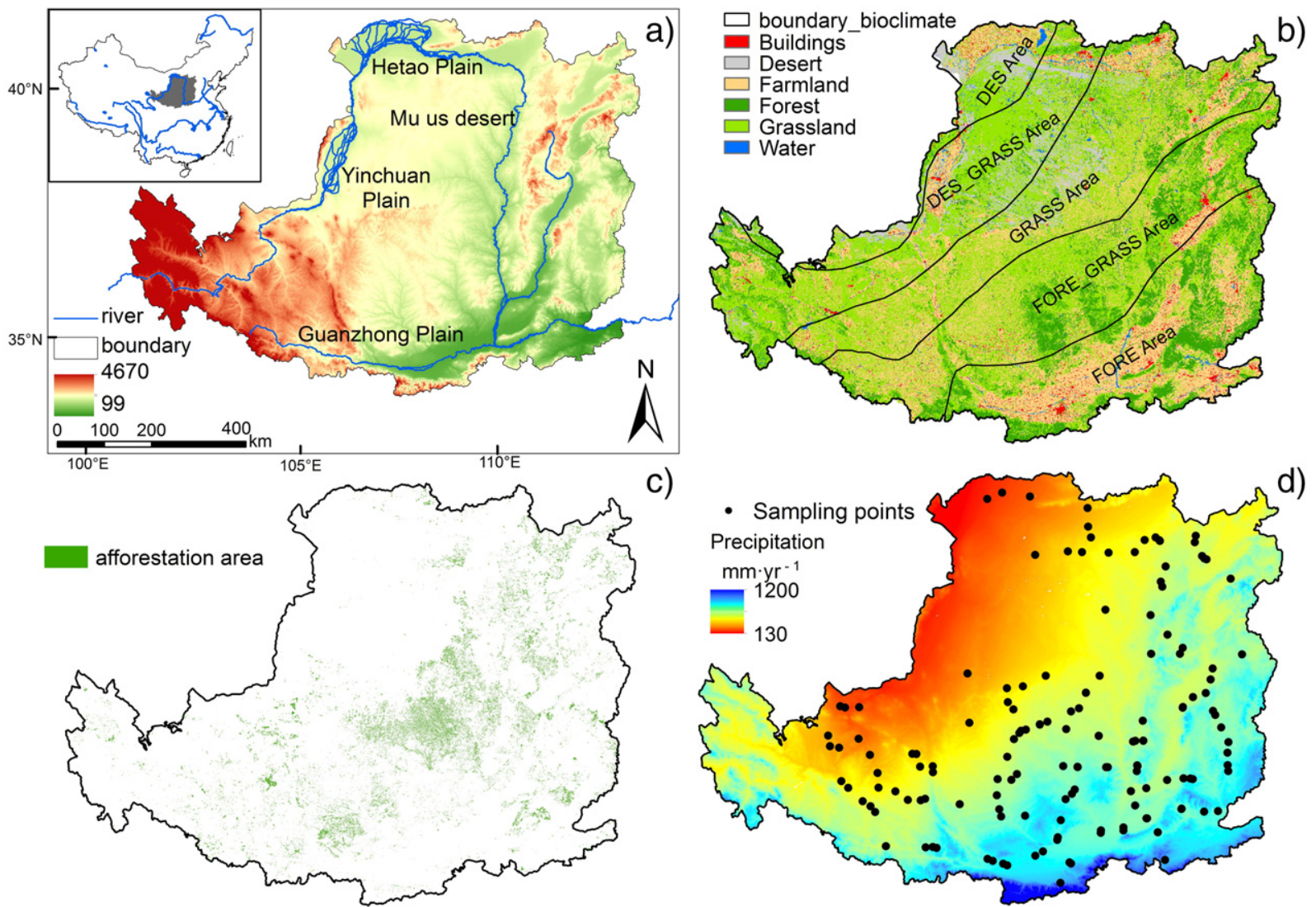

Fig. 1. Overview of the Loess Plateau. (a) Location of the Loess Plateau, (b) land use, (c) re-vegetation area and (d) annual precipitation and soil sampling sites.

grasslands, arid and semi-arid desert-grasslands through to arid deserts (Fig. 1b, X. M. Feng et al., 2013; Q. Feng et al., 2013). According to the water resource available to the local ecosystem, the Loess Plateau can be divided into different components: a loess hilly area in the southeast, the Muus desert in the northern part and the irrigated areas (Fig. 1a). Precipitation is the only water input for ecosystems in the loess hilly area and the Mu us desert, where re-vegetation mainly occurred. The irrigation areas are croplands in the Hetao plain, Yinchuan plain and Guanzhong plain (Fig. 1a). The irrigation water for the Hetao plain and Yinchuan plain is from the surface flow of the Yellow River; however, in the Guanzhong plain irrigation is supplied by both surface flow and groundwater (Kou and Li, 1985; Li et al., 2014).

During 2003-2011, the climate of the Loess Plateau underwent a non-significant inter-annual drying and warming change. The trends of precipitation are $-5.96 \mathrm{~mm} \mathrm{yr}^{-1}(\mathrm{p}=0.53),-7.08 \mathrm{~mm} \mathrm{yr}^{-1}$ ( $\mathrm{p}=0.37$ ) and $1.12 \mathrm{~mm} \mathrm{yr}^{-1}(\mathrm{p}=0.66)$ for the annual average, and values in the growing season and non-growing season, respectively. The trends of temperature are $0.022^{\circ} \mathrm{C} \mathrm{yr}^{-1}(\mathrm{p}=0.71), 0.09{ }^{\circ} \mathrm{C} \mathrm{yr}^{-1}$ $(\mathrm{p}=0.24)$ and $-0.045^{\circ} \mathrm{C} \mathrm{yr}^{-1}(\mathrm{p}=0.42)$ for the annual average, and values in the growing season and non-growing season, respectively (See Fig. 2).

\subsection{Datasets}

\subsubsection{In-situ soil moisture measurement}

In our study, the in-situ measurements of SM are a subset of those made by H. Wang et al. (2010) and Y. Q. Wang et al. (2010), these data come from the most intensive soil sampling across the entire Loess Plateau. The sites of soil sampling were chosen randomly; however, they do cover different land-use types (e.g., farmland, woodland and grassland) in the Loess Plateau. The soil sampling was conducted between 9 April and 6 November 2008, using a soil auger. Soil sampling with an auger is the main method of collecting reliable soil moisture data at regional scale, not only in the Loess Plateau ( $\mathrm{H}$. Wang et al., 2010; Y. Q. Wang et al., 2010), but also in other areas without an automatic monitoring network (Celano et al., 2011). However the method is limited to the first $10-\mathrm{cm}$ of the soil profile. For soil sampling with an auger, the measurements over the depth 0 to $10 \mathrm{~cm}$ are considered representative of the in-situ surface layer suitable for comparison to satellite observation, as for example by Peng et al. (2015). We also use the measurements in this layer as the ground truth of SM in this study. The SM was derived gravimetrically as the weight loss of previously sealed soil samples after oven drying at $105^{\circ} \mathrm{C}$ to constant mass. The soil measurements taken by H. Wang et al. (2010) and Y. Q. Wang et al., (2010) (see Fig. 1d for their locations) were filtered for clear sky conditions and

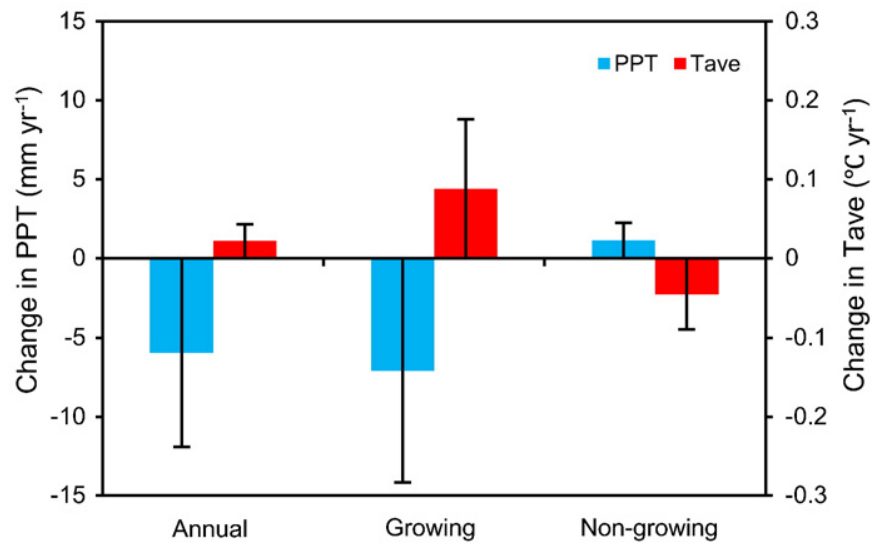

Fig. 2. Change in average precipitation (PPT, blue) and change in average temperature (Tave, red) in the Loess Plateau over the study period 2003-2011. The annual change is shown on the left, with the change in the growing season and non-growing season shown separately. 
MODIS LAI

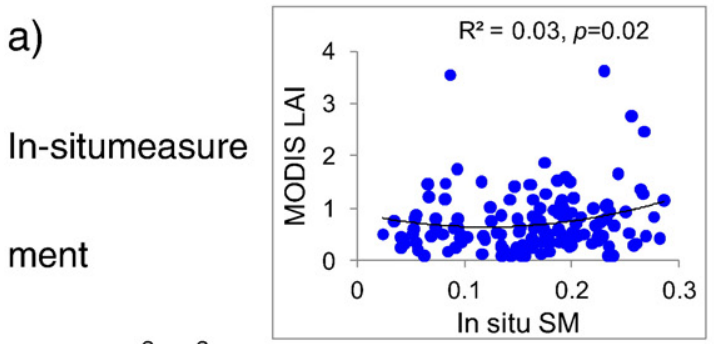

$\left(1 \mathrm{~km}, \mathrm{~m}^{3} \mathrm{~m}^{-3}\right)$

b) JAXA

$\left(25 \mathrm{~km}, \mathrm{~m}^{3} \mathrm{~m}^{-3}\right)$

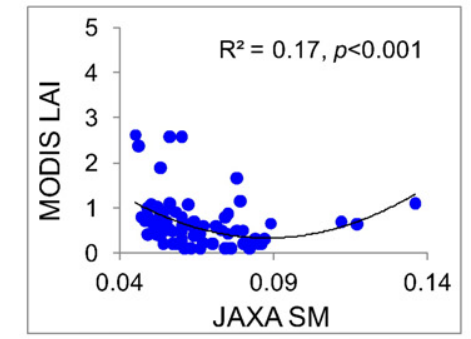

c) LPRM-C

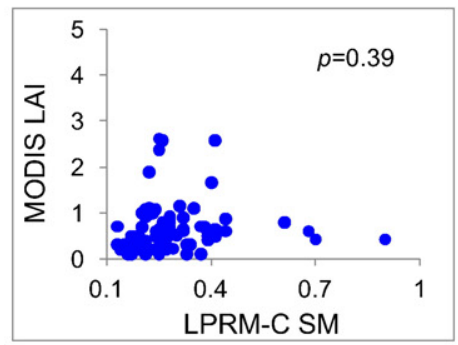

d) LPRM-X

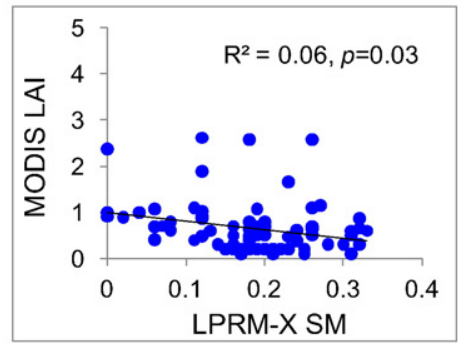

e) NSIDC

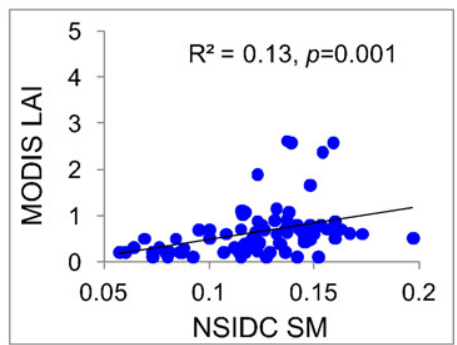

MODIS LST $\left({ }^{\circ} \mathrm{C}\right)$
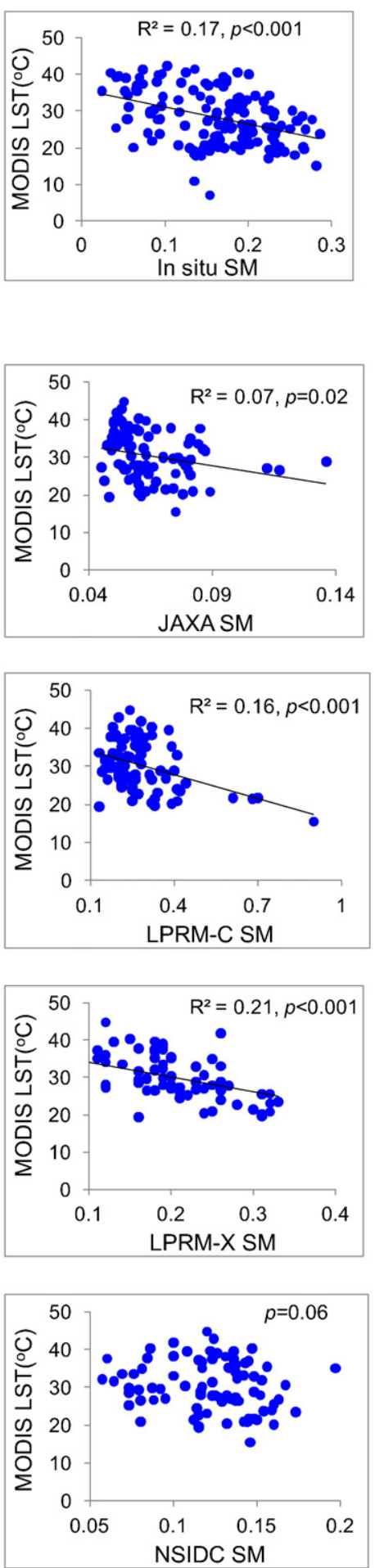

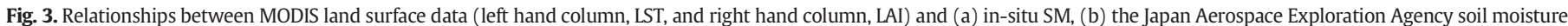
product (JAXA), (c) the C-band soil moisture product (LPRM-C) and the X-band soil moisture product (LPRM-X) and (e) the NASA standard soil moisture product (NSIDC).

140 samples were selected for comparison with satellite observations (see Methods 3.1). Gravimetric soil-water content $\left(\theta_{\mathrm{m}}, \mathrm{kg} \mathrm{kg}^{-1}\right)$ was converted to soil moisture $\left(\theta_{\mathrm{v}}, \mathrm{m}^{3} \mathrm{~m}^{-3}\right)$, using soil bulk density $(\rho$, $\mathrm{kg} \mathrm{m}^{-3}$ ) and water density $\left(1000 \mathrm{~kg} \mathrm{~m}^{-3}\right)$ with the equation:

$\theta_{\mathrm{v}}=\theta_{\mathrm{m}} \rho / 1000$

\subsubsection{AMSR-E soil moisture}

Satellite-mounted microwave radiometers are the preferred instruments for studying soil moisture - vegetation attenuation effects on the signal and atmospheric effects are low (Njoku and Entekhabi, 1996; Schmugge, 1978). AMSR-E is a passive microwave scanning radiometer, operating at six wavelengths within the microwave spectrum 

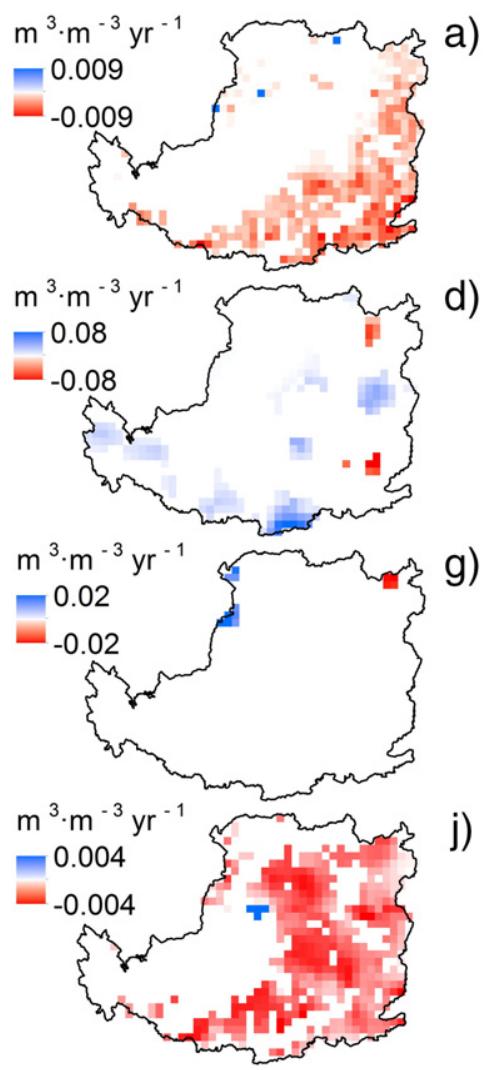

d)

g)

j)
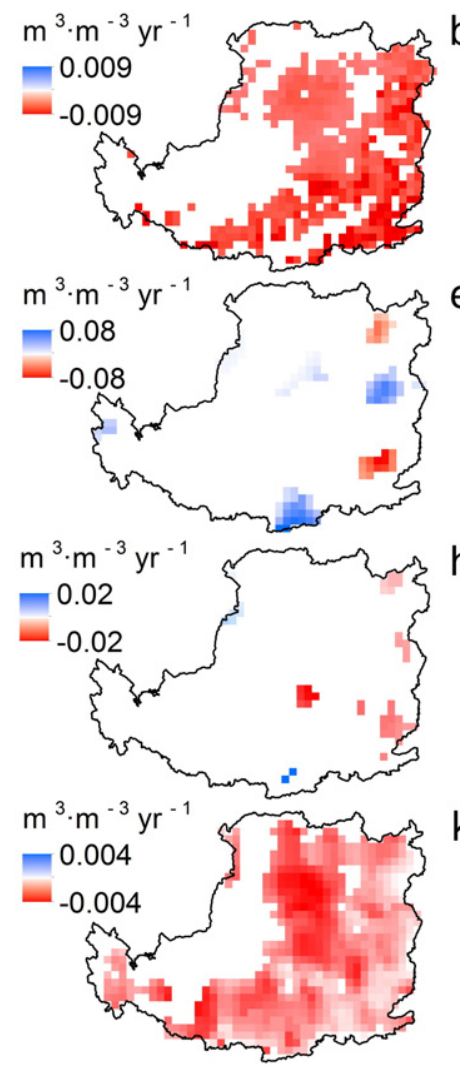

b)

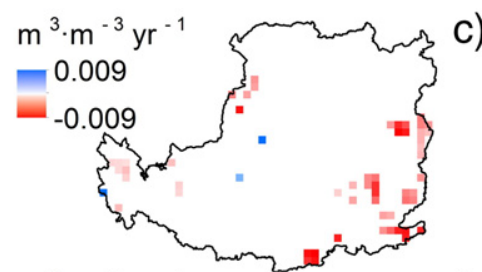

e)

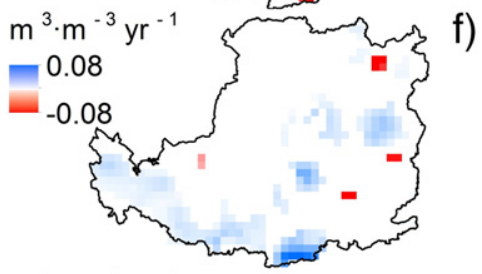

h)

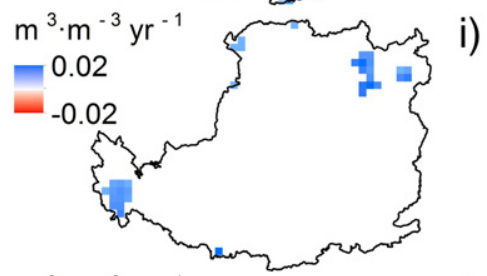

k)

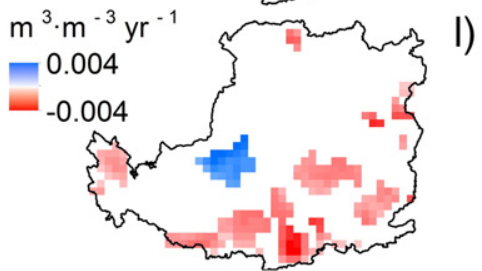

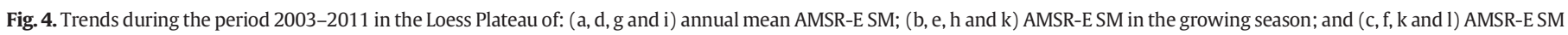

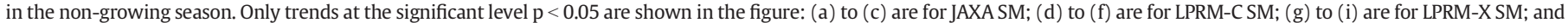
(j) to (l) are for NSIDC SM.

$(6.925,10.65,18.7,23.8,36.5$, and $89 \mathrm{GHz})$ with horizontal and vertical polarizations. It was flown on NASA's Aqua satellite. AMSR-E SMs in our study are the ascending level 3 products, including the NASA standard soil moisture product (NSIDC, http://nsidc.org/data/AE_Land3) (Njoku and Chan, 2006), the Japan Aerospace Exploration Agency (JAXA) soil moisture product (https://gcom-w1.jaxa.jp/) (Koike et al., 2004), and both the C-band $(6.925 \mathrm{GHz})$ and X-band $(10.65 \mathrm{GHz})$ soil moisture products developed using the Land Parameter Retrieval Model (hereafter called LPRM-C and LPRM-X products, http:// www.falw.vu/ jeur/lprm/index.html) (Owe et al., 2008). AMSR-E stopped acquiring observations in mid-October 2011. The soil moisture is provided as a re-sampled product at $25 \mathrm{~km}$ resolution. Daily soil moisture datasets covering the entire Loess Plateau region were downloaded for the period between June 2003 and October 2011. Our study was conducted both for the complete year and separately for the growing and non-growing seasons from the year 2003 to 2011.
AMSR-E soil moisture algorithms (NSIDC, JAXA, LPRM) are based on the same radiative transfer equation, representing the passive microwave electromagnetic radiation emitted by the Earth's surface (Mo et al., 1982). Besides soil moisture, the radiative transfer equation includes parameters describing the vegetation properties (vegetation optical depth, single scattering albedo and surface roughness) and temperature. Algorithms differ in how these parameters are used to derive soil moisture.

The NSIDC method performs a multivariate optimization minimizing the discrepancy between model simulations and satellite observations of the variable retrievals, i.e., soil moisture, vegetation optical depth, and the effective soil temperature (Njoku et al., 2003). The method was originally designed for the $\mathrm{C}$ - and X-band channels, however severe radio-frequency interference was discovered within $C$ band (over the United States and Japan) and X band (over Italy and Great Britain) (Li et al., 2004). For this reason, the retrieval algorithm was applied to the X-band and Ku-band $(18.7 \mathrm{GHz})$ channels. The disadvantage of
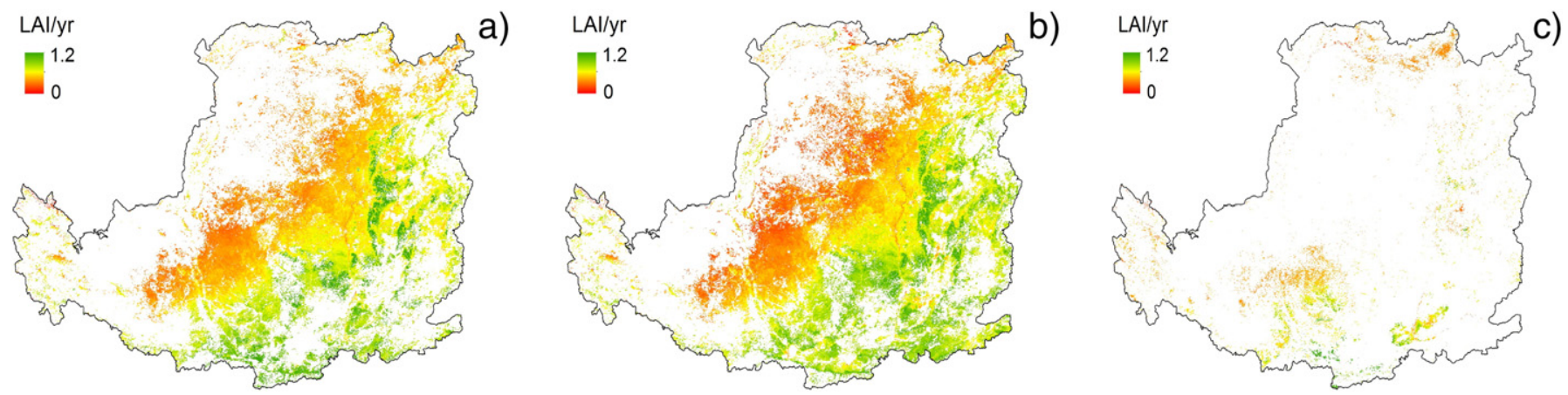

Fig. 5. Trends of MODIS LAI ( $<$ 0.01) (a) for yearly values, (b) for the growing season and (c) for the non-growing season. 


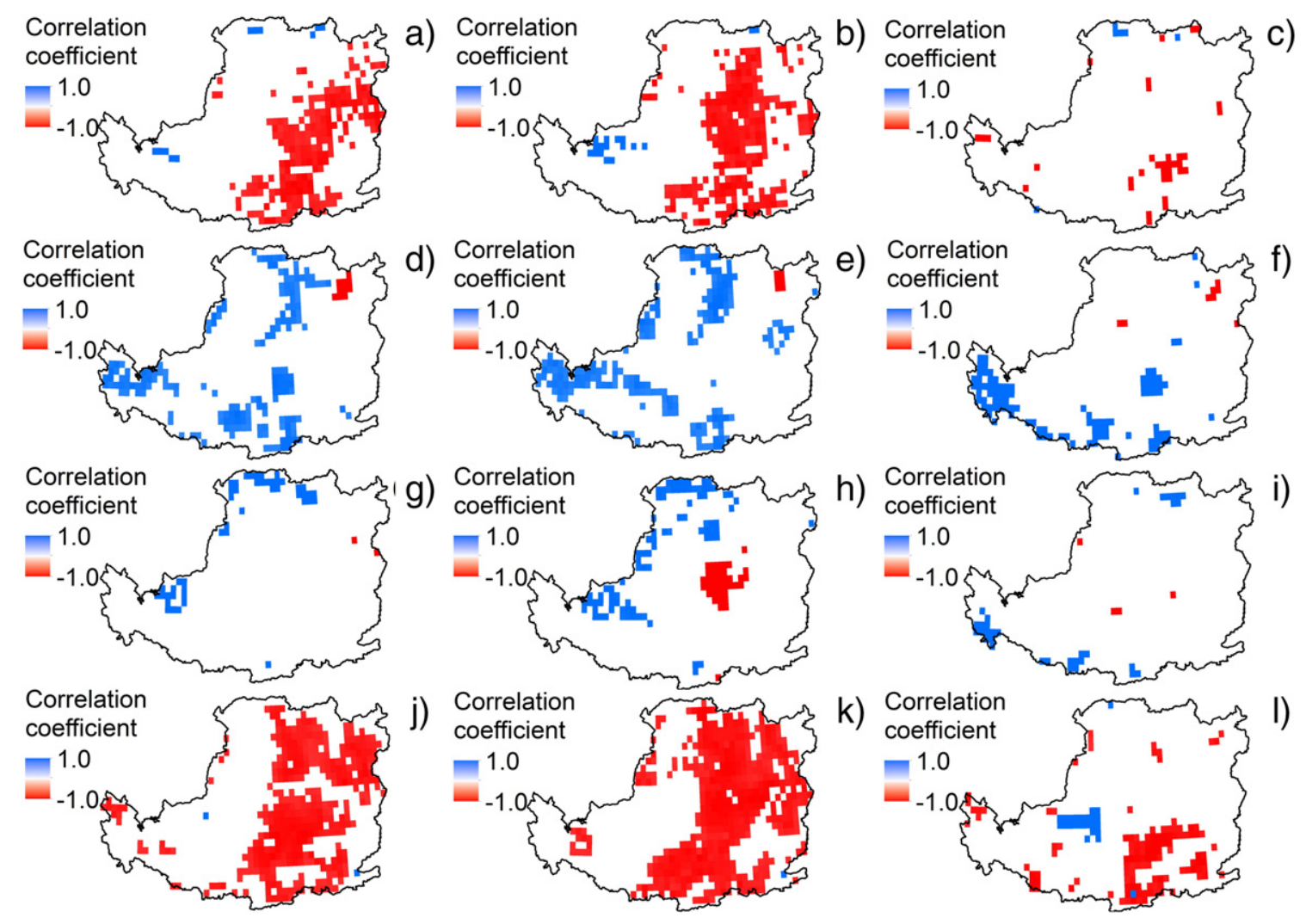

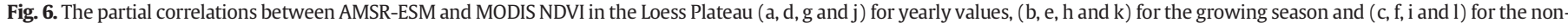

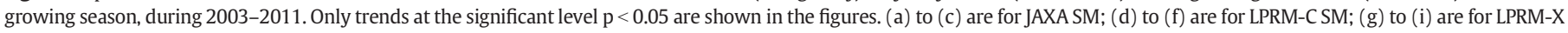
SM; and (j) to (l) are for NSIDC SM.
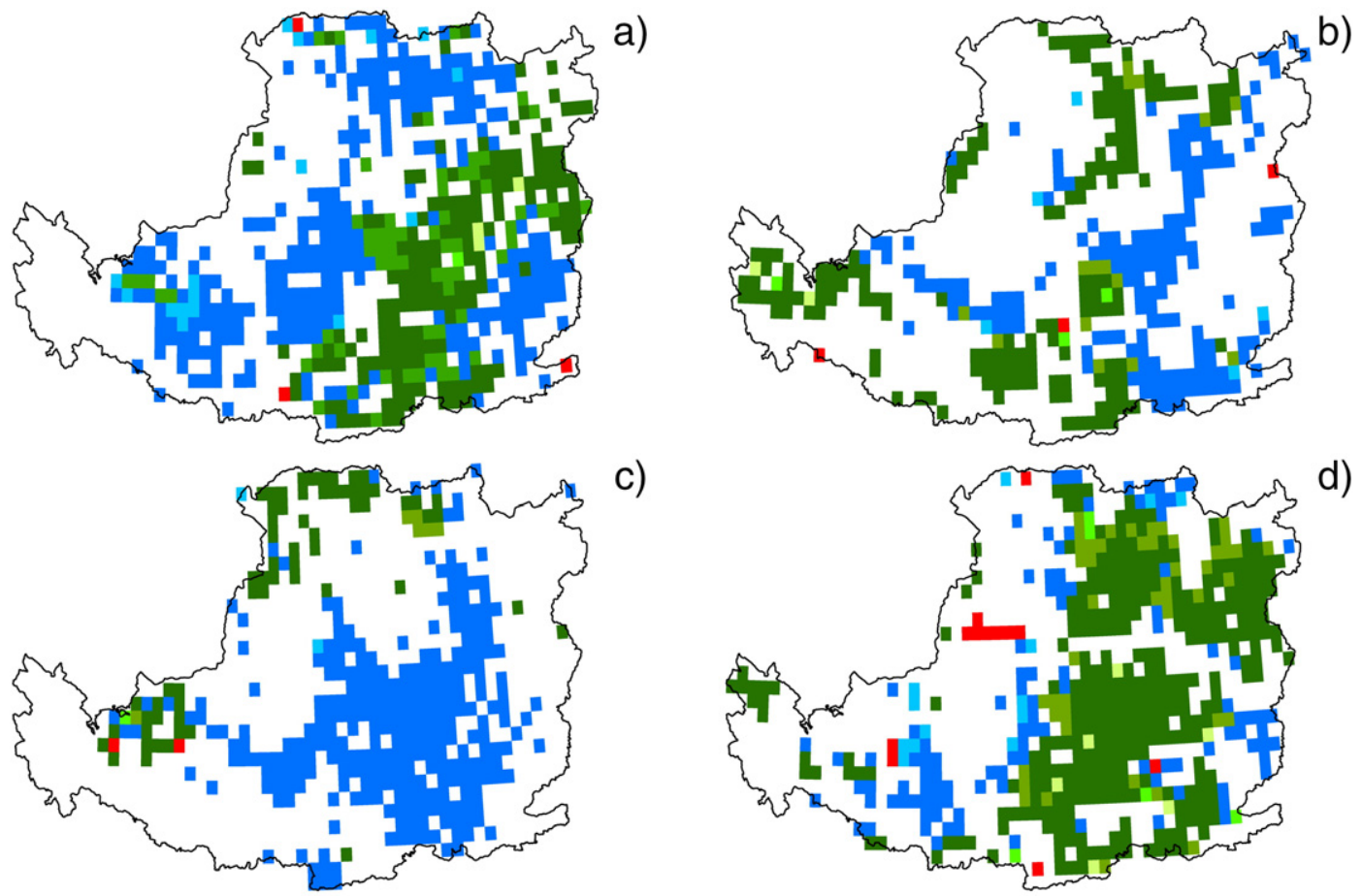

\section{Dominant factors}

LAI $\square$ LAI、PPT $\square$ LAI、PPT、Tave $\square$ LAI、Tave

PPT $\square$ PPT、Tave $\square$ Tave

Fig. 7. Integrated roles of climate and re-vegetation on AMSR-E SM change during 2003-2010. (a) JAXA SM, (b) LPRM-C SM, (c)LPRM-X SM, (d)NSIDC SM. 
this adjustment is that the brightness temperature recorded by the $18.7 \mathrm{GHz}$ channel is more influenced by the atmosphere and vegetation compared to the lower frequencies.

In the JAXA algorithm, a look-up table is used to estimate soil moisture and vegetation water content simultaneously (Koike et al., 2004). A forward radiative transfer scheme is first used to generate brightness temperatures for a wide range of parameter values (soils and vegetation) for multiple frequencies and polarizations. Then, the datasets of brightness temperature are used to create look-up tables. Finally, soil moisture and vegetation water content are estimated from the $10.65 \mathrm{GHz}$ data and the index of soil wetness (ISW) (Koike et al., 1996) from $36.5 \mathrm{GHz}$ and $10.65 \mathrm{GHz}$ horizontal channels. The JAXA algorithm assumes that the vegetation optical depth is linearly related to vegetation water content which can be determined from optical data by the NDVI.

The LPRM method retrieves soil moisture, vegetation optical depth, and surface temperature separately. The vegetation optical depth is expressed as a function of the soil dielectric constant and the microwave polarization difference index; this avoids the need for additional vegetation datasets (Meesters et al., 2005). The land surface temperature is derived independently from the vertically polarized Ka-band $(36.5 \mathrm{GHz})$ observations of AMSR-E by using an empirical regression model (Holmes et al., 2009). Thus, soil moisture is the only unknown variable in the radiative transfer equation and can be obtained through a nonlinear iterative procedure. LPRM-C and LPRM-X use C-band and X-band observations for soil moisture retrieval, respectively. The LPRM does not need any ancillary data, and is thus considered to have the greatest potential for estimating soil moisture on a global scale. However, the estimation of surface temperature in LPRM is from a global empirical regression model, which was developed on the physical basis that the Ka-band vertical brightness temperature is highly sensitive to the surface temperature (Holmes et al., 2009; Mladenova et al., 2014). However, the ground measurements that were used to establish the empirical model were mainly from the United States and some European countries. It may, therefore, have regional dependence and be inapplicable outside those regions.

Validations of AMSR-E were performed in Europe (Albergel et al., 2012), the United States (Jackson et al., 2010, 2012) and Australia (Draper et al., 2009), fewer were conducted in Asia. As for validation of AMSR-E in the Tibetan Plateau: JAXA and LPRM products give reasonable results in terms of correlation when compared to that from the in-situ monitoring network; however the NASA product significantly underestimates the soil moisture and also lacks temporal dynamics (Zeng et al., 2015). Because of their environmental and scientific significance, these globally applied products require more evaluation in regions other than AMSR-E algorithmestablished area. A new method of evaluation is also needed for areas where a network of in-situ moisture measurements is not technically feasible, for example our study area, the Loess Plateau.

\subsubsection{MODIS data}

Land surface temperature (LST) and vegetation cover can be combined and used as an alternative to passive microwave sensors providing information on moisture conditions at the surface (Sandholt et al., 2002; Holzman et al., 2014). Our study used land surface products of the Moderate Resolution Imaging Spectroradiometer (MODIS) in evaluating the AMSR-E SM. MODIS data are at 1-km spatial resolution and cover the period 2003-2011 (https://ladsweb.nascom.nasa.gov/data/ search.html). The dataset includes LST and leaf area index (LAI). The MODIS land surface products cover the same period as the AMSR-E soil moisture data from 1 January 2003 to 3 November 2011 with a temporal resolution of 8 days. Annual LAI was the maximum value of 8 -day MODIS LAI in each year.

\subsubsection{Climate data}

Daily meteorological data (precipitation and temperature) for the period 2003-2011 were acquired from 172 stations within and near the Loess Plateau. These meteorological station data were interpolated into 1-km resolution maps using ANUSPLIN 4.2 (Feng et al., 2012) and combined with topographic data (1-km resolution from the Shuttle Radar Topography Mission, or SRTM). The climate data interpolation method provides accurate estimates of spatial climatic variables by including the linear covariates to represent the dependence of atmospheric pressure and temperature on altitude (Hutchinson, 1991). In the interpolation with ANUSPLIN, different spline models, including bi-variate thin plate spline, tri-variate partial thin plate spline and trivariate thin plate spline were evaluated for the fitting test. The model applied to generate the meteorological map was the one with the lowest signal-to-noise ratio and fitting error. In a final step, annual precipitations maps were constructed from the daily site precipitation data, and annual mean temperature maps were obtained from the daily temperature measurements.

\section{Methods}

The evaluation of AMSR-E retrieval comprises two parts. First, we compared AMSR-E SM with the in-situ moisture data. Second, we analyzed the possible reasons behind the response of AMSR-E SM to massive re-vegetation in the Loess Plateau by comparing AMSR-E SM against MODIS land surface products.

\subsection{Comparison with in-situ moisture}

The Loess Plateau has no automatic soil moisture monitoring network and a validation method based on long-term in-situ monitoring is therefore not possible. All the soil moisture data used here were collected with soil augers during an in-situ soil moisture measurement campaign conducted over a period of seven months. Sampling covered the entire Loess Plateau. The dataset thus comprises instantaneous insitu measurements marked by different sampling times. Moreover, because of the scale mismatch, it is impossible to validate AMSR-E SM directly by comparison with in-situ measurements (Cheema et al., 2011; Dall'Amico et al., 2012; Tuttle and Salvucci, 2014). The method we propose here is based on the "Universal Triangle" concept (Chauhan et al., 2003; Piles et al., 2011; Im et al., 2016). This method is based on an interpretation of the image (pixel) distribution in space of land surface temperature (LST) versus vegetation cover (VC). If a sufficiently large number of pixels are present and when cloud, surface water and outliers are removed, the shape of the pixel envelope resembles a triangle, and the slope of a plot of LST versus VC is determined by the surface soil moisture. The triangle concept was first introduced by Price (1990) and later elaborated upon by Carlson et al. (1994, 1995), Gillies and Carlson (1995), Lambin and Ehrlich (1996), Gillies et al. (1997), Owen et al. (1998) and by Islam and his associates (Jiang and Islam, 1999, 2001, 2003). Taking SRT as a VC independent variable, the "Universal Triangle" concept has been widely applied in quantifying surface soil moisture (Sandholt et al., 2002; Sánchez-Ruiz et al., 2014), as an alternative to passive microwave sensing. In SRT-VC space formed with remotely sensed observations, satellite-derived land surface temperature and vegetation index are the most commonly used indices (Sandholt et al., 2002). A virtue of the triangle method is that regardless of the net radiation or changes in ambient temperature from one day to the next (such as might occur after the passage of a cold front) or differences in the satellite or aircraft measurement times, a similar triangle is generated over a succession of days (Sandholt et al., 2002). Another virtue of the triangle is the stability of the data at different spatial resolutions. The triangle method has been applied to data with different spatial resolutions from in-situ sampling to NOAA-AVHRR data (Sandholt et al., 2002). A typical application is downscaling of coarseresolution satellite soil moisture. Sánchez-Ruiz et al. (2014) declared that the accuracy of the coarse spatial resolution SMOS product $(\sim 40 \mathrm{~km})$ is maintained when soil moisture is downscaled to high resolution $(500 \mathrm{~m})$, using a triangle framework together with satellitederived land surface temperature and vegetation index. The main weakness of the triangle method is that it requires some subjectivity in 
identifying the warm edge, and the dense vegetation and bare soil extremes. The method in our analysis takes advantage of the virtues of the triangle method. However due to the limited dataset, instead of forming a pixel-enveloped triangle, we propose to compare the AMSR-E SM with the MODIS land surface data (i.e., MODIS LAI, LST in this study), which were up-scaled with a nearest neighbor algorithm to the data resolution of $25 \mathrm{~km}$. Simultaneously, ground-based soil moisture measurements were compared with the commonly used MODIS land surface data at the finer data resolution of $1 \mathrm{~km}$ by fitting a statistical relationship. We assume that AMSR-E SM matches the ground truth in spatial and temporal patterns if the relationships between AMSR-E SM and MODIS land surface products are consistent with those between in-situ soil moisture measurements and MODIS land surface data.

Before validation of AMSR-E SM, satellite observations were collected to match the location and sampling date of the in-situ measurements. The satellite observations include 81 data points of JAXA SM, 81 data points of LPRM-C SM, 77 data points of LPRM-X SM and 78 data points of NSIDC SM. The smaller number of satellite observations compared to the in-situ measurements ( 140 samples) results from multiple sampling sites being contained within one AMSR-E SM pixel $(25 \mathrm{~km} \times 25 \mathrm{~km})$, as well as the absence of satellite data (i.e., MODIS LST) on cloudy days.

\subsection{The response of AMSR-E SM to massive re-vegetation in the Loess Plateau}

Trends of SM and land cover in the Loess Plateau, including annual mean AMSR-E SM, annual mean MODIS LAI, AMSR-E SM and MODIS $\mathrm{LAI}$ in the non-growing season as well as in the growing season, were estimated by linear regression against time. The regression coefficients were used to indicate the general trend in SM $\left(\mathrm{m}^{3} \mathrm{~m}^{-3} \mathrm{yr}^{-1}\right)$ and land cover over the study period. A positive value of regression coefficient represents an increasing trend and vice versa. If the regression coefficient passes the significance test $(p<0.05)$, it indicates the trend is significant at the $95 \%$ confidence interval. When the regression coefficient passes the significance test of $\mathrm{p}<0.01$, the trend is extremely significant.

The partial correlation method was used to study the response of soil moisture to re-vegetation. Partial correlation is used in diagnosing the correlation between two signals by eliminating the influence of other signals in a complex system. It has been used in fields containing a large number of interactions, such as ecology, climatology, and vegetation response to climate warming (Hald, 1952; Yuan et al., 2015; Zhou et al., 2000). In the response of soil moisture change to re-vegetation, partial correlation analysis provides the correlation between the fluctuation in AMSR-E SM and MODIS LAI, while controlling the other factors impacting soil moisture, e.g., climatic factors such as precipitation and temperature. The correlation is significant at the $95 \%$ confidence interval when it passes the significance test of $\mathrm{p}<0.05$.

Multiple regression analysis was conducted with SAS software to determine the spatial variance in the response of soil moisture to revegetation. In the multiple regression analysis, annual precipitation and annual temperature were included as factors impacting AMSR-E $\mathrm{SM}$, in addition to MODIS LAI. The final impacting factors are those passing the significance test $(\mathrm{p}<0.05)$ in the regression analysis.

\section{Results}

\subsection{Comparison with in-situ soil moisture}

The in-situ soil moisture measurement is negatively correlated with MODIS LST ( $p<0.001)$. The relationship between in-situ soil moisture measurement and MODIS LAI is nonlinear ( $p=0.02$ ), with the lowest LAI corresponding to the median value of in-situ measurement $\left(0.15 \mathrm{~m}^{3} \mathrm{~m}^{-3}\right)$. It is worth noting that the in-situ soil moisture data we collected represents instantaneous measurements at different times covering different sites over the entire Loess Plateau. Due to the insufficient number of pixels, our data were a subset rather than shaping the complete triangle in the LST-LAI space (see Methods 3.1). The derived relationships are highly dependent on where the data pixel falls within the complete triangle of the Loess Plateau. Nevertheless, it is an efficient reference for evaluating satellite-derived AMSR-E SM.

JAXA SM shows the same relationship with MODIS LAI/LST as that of the in-situ soil moisture measurements: nonlinear correlation with MODIS LAI, $\mathrm{p}<0.001$, with the lowest LAI corresponding to the median range of AMSR-E SM $0.09 \mathrm{~m}^{3} \mathrm{~m}^{-3}$; and negatively correlated with MODIS LST, $\mathrm{p}=0.02$. Consistent with the in-situ measurements, both LPRM-C SM and LPRM-X SM are negatively correlated with MODIS LST $(\mathrm{p}<0.001)$. However, neither LPRM-C SM, LPRM-X SM nor NSIDC show the same relationship with MODIS LAI as that shown by the insitu measurements. Moreover, the relationship between NSIDC SM and MODIS LST are statistically non-significant $(\mathrm{p}=0.06)$. (See Fig. 3 )

We conclude that JAXA SM better captures the spatiotemporal variation of SM in the Loess Plateau compared to other AMSR-E retrievals, since it agrees with the in-situ measurements not only in its relationship with MODIS LAI, but also with MODIS LST; although it does differ from the in-situ measurements in data range $\left(0.16 \pm 0.06 \mathrm{~m}^{3} \mathrm{~m}^{-3}\right.$ for insitu SM; $0.07 \pm 0.02 \mathrm{~m}^{3} \mathrm{~m}^{-3}$ for JAXA SM; $0.28 \pm 0.13 \mathrm{~m}^{3} \mathrm{~m}^{-3}$ for LPRM-C SM; $0.19 \pm 0.08 \mathrm{~m}^{3} \mathrm{~m}^{-3}$ for LPRM-X SM; $0.12 \pm$ $0.03 \mathrm{~m}^{3} \mathrm{~m}^{-3}$ for NSIDC SM).

\subsection{The response of AMSR-E SM to massive re-vegetation in the loess plateau}

In line with the ground truth (Yang et al., 2014; Feng et al., 2016), JAXA SM in the Loess Plateau decreased during 2003-2010. The significant decrease occurred in the southeastern sector, occupying 39.0\% of the entire region (Fig. 4a). The decrease of AMSR-E SM mainly occurred in the growing season (at a rate of $-0.003 \mathrm{~m}^{3} \mathrm{~m}^{-3} \mathrm{yr}^{-1}, \mathrm{p}=0.007$ ). The area showing a decrease with JAXA SM was $56.5 \%$ of the entire region in the growing season, including both in the southeastern and central sectors of the Loess Plateau (Fig. 4b). In contrast, JAXA SM in the non-growing season remained stable with non-significant change $(\mathrm{p}=0.48$, Fig. $4 \mathrm{c})$.

Neither LPRM-C SM nor LPRM-X SM changed remarkably during the study period. Change in LPRM-C SM mainly occurred in the nongrowing season, showing a slight increasing trend $\left(0.12 \mathrm{~m}^{3} \mathrm{~m}^{-3} \mathrm{yr}^{-1}\right.$, $\mathrm{p}=0.29$, Fig. $4 \mathrm{f}$ ). However, change in LPRM-X SM is not significant either in the growing season ( $\mathrm{p}=0.43$, Fig. $4 \mathrm{~h}$ ) or in non-growing season $(\mathrm{p}=0.49$, Fig. 4i). LPRM-C SM and LPRM-X SM failed to detect the decrease of soil moisture in the re-vegetated sectors during the drier and warmer period of 2003-2011 in the water-limited Loess Plateau.

NSIDC SM decreased during 2003-2010 (at a rate of $-0.001 \mathrm{~m}^{3} \mathrm{~m}^{-3} \mathrm{yr}^{-1}, \mathrm{p}=0.02$ ). The decrease of NSIDC SM is substantial in comparison to that from JAXA SM, with the area experiencing significant decrease being $46.6 \%$ of the entire region (Fig. 4j). NSIDC SM decreased mostly in the growing season at the rate of $-0.002 \mathrm{~m}^{3} \mathrm{~m}^{-3} \mathrm{yr}^{-1}(\mathrm{p}=0.01)$. The significant decrease occupied $67.2 \%$ of the entire region, mostly in the southeastern and central sectors of the Loess Plateau (Fig. $4 \mathrm{k}$ ). In the non-growing season, NSIDC $\mathrm{SM}$ decreased at the rate of $-0.001 \mathrm{~m}^{3} \mathrm{~m}^{-3} \mathrm{yr}^{-1}(\mathrm{p}=0.04)$ and the area experiencing significant decrease was $19.0 \%$ of the entire region (Fig. 4l).

\subsubsection{The impact of re-vegetation AMSR-E SM in the Loess Plateau}

Fig. 5 shows that MODIS LAI in the Loess Plateau increased continuously during 2003-2011, at the rate of $0.33 \mathrm{yr}^{-1}(\mathrm{p}=0.005)$, responding to the increased plant growth due to re-vegetation. The location of the significant increase in MODIS LAI (central part of the Loess Plateau, Fig. 5a) is consistent with the areas of re-vegetation (Fig. 1c), and where land-cover change can be detected from satellite 
observations. The increase of MODIS LAI mainly occurred in the growing season (at the rate of $0.46 \mathrm{yr}^{-1}, \mathrm{p}=0.005$ ) - it was less significant in the non-growing season both in spatial extent and in the changing rate $\left(29.1 \%\right.$ of the entire region, at the rate of $0.19 \mathrm{yr}^{-1}, \mathrm{p}=0.01$ ). The increase of plant growth following re-vegetation is expected to cause the decrease of soil moisture in the Loess Plateau, in particular in a drying and warming period (see Section 2.1).

In general, over the entire Loess Plateau, the partial correlation coefficients between MODIS NDVI and JAXA SM show that any decrease in surface soil moisture due to plant growth after revegetation was not significant. However, looking at the spatial distribution, the significant partial correlations between MODIS NDVI and JAXASM are found in the re-vegetated areas (Fig. 4a and b). It is worth noting that in only part of the re-vegetated area was there a significant decrease of JAXA SM. It is calculated that re-vegetation resulted in a $22.33 \%$ decrease in the area of annual JAXA SM and a 2 $7.08 \%$ decrease in the area of JAXASM in the growing season. The spatial inconsistency between the re-vegetation area and the area of decreased JAXASM suggests that other factors are impacting the variance of SM. Re-vegetation had no impact on surface soil moisture in the non-growing season, indicated by the non-significant yearly partial correlation coefficients between plant growth and JAXASM (coefficient $-0.32, \mathrm{p}=0.41$, Fig. $4 \mathrm{c}$ ).

Spatially, re-vegetation caused the area of annual NSIDC SM to decrease over $36.29 \%$ of the entire Loess Plateau region. The significant partial correlations between MODIS NDVI and NSIDC SM were mostly found in the re-vegetated areas (52.7\% re-vegetated area). However, the impact of re-vegetation on soil moisture is barely detectable using LPRM-C SM and LPRM-X SM. Re-vegetation is only related to $17.5 \%$ of the area of decreased annual LPRM-C SM and $4.69 \%$ of the area of decreased annual LPRM-C SM.

\subsection{Spatially varying response of soil moisture to re-vegetation}

Besides re-vegetation, climate factors also impact soil moisture. In the Loess Plateau, during the study period of 2003-2011, the effect of temperature was limited (the partial correlation coefficient $0.14, \mathrm{p}=$ 0.53 for yearly values); however, precipitation was significantly and positively related with JAXA SM (the partial correlation coefficient $0.64, p=0.19$ for yearly values). For the entire Loess Plateau, precipitation, re-vegetation and their combination dominated JAXA SM change in $26.97 \%, 15.62 \%$ and $6.31 \%$ of the area respectively, spreading from northwest to southeast following the precipitation gradient (Fig. 7a). Areas of different impact factors are consistent with the overlaid results of maps of re-vegetation, JAXA SM change, indicating that climate factors were the cause of the spatial inconsistency of areas between revegetation and decreased JAXA SM. For those areas outside the revegetated sector, precipitation dominates the decrease of JAXASM over $11.7 \%$ of the area of the Loess Plateau. No impact of climate factors was detected in irrigated areas, e.g., Yinchuan plain, Hetao plain and Guanzhong plain (Figs. 7a and Fig. 1a).

Precipitation, re-vegetation and their combination dominated LPRM-C SM change in $15.51 \%, 16.02 \%$ and $1.47 \%$ of the area respectively. And the combination of re-vegetation, precipitation and temperature dominated LPRM-C SM change in $0.3 \%$ of the entire area (Fig. $7 \mathrm{~b}$ ). For LPRM-X SM, precipitation, re-vegetation and their combination dominated SM change in $27.79 \%, 4.02 \%$ and $2.05 \%$ of the area respectively (Fig. 7c). Clearly, LPRM-X SM overlooks the role of precipitation in soil moisture change; however, LPRM-X SM ignores the role of revegetation in soil moisture change. For NSIDC SM, precipitation, revegetation and their combination dominated NSIDC SM change in $10.74 \%, 30.75 \%$ and $4.46 \%$ of the area respectively (Fig. $7 d$ ). Compared to that with the JAXA SM, the role of precipitation in soil moisture decrease is reduced by NSIDC SM, while the role of re-vegetation is amplified.

\section{Discussion}

\subsection{Evaluation of AMSR-E retrieval in the Loess Plateau}

According to the in-situ measurements made in particular field surveys across different precipitation gradients, SM spatial variability was most highly correlated with rainfall over the Loess Plateau, particularly for SM in the surface layer (Jin et al., 2011). For re-vegetation, although the roots of the species most widely planted in the Loess Plateau (e.g., Caragana korshinskii, Hippophae rhamnoides, Pinus tabuliformis, and Robinia pseudoacacia) can reach as deep as $2.8 \mathrm{~m}$ (Jian et al., 2014), the majority of absorbing roots, which influence the measured soil moisture most strongly, are concentrated in the upper $60 \mathrm{~cm}$ of soil (Wang et al., 2009). In particular roots for the grasses are concentrated in the upper $20 \mathrm{~cm}$ (Deng et al., 2016). Re-vegetation causes the soil moisture in the upper layer (the upper $20 \mathrm{~cm}$ according to Deng et al., 2014) of soil depth to decrease. However, the role of precipitation is estimated to be statistically non-significant when using LPRMC SM (the partial correlation coefficient $0.45, \mathrm{p}=0.33$ for yearly values). The effect of re-vegetation, is not detectable using LPRM-X SM (the partial correlation coefficient $0.02, \mathrm{p}=0.48$ for yearly values). For NSIDC $\mathrm{SM}$, re-vegetation plays a more important role than precipitation in causing the soil moisture change (Fig. 6d). In contrast, analysis with JAXA SM suggests precipitation plays the most important role in causing soil moisture to change (the partial correlation coefficient $0.64, \mathrm{p}=0.19$ for yearly values), followed by re-vegetation as indicated by MODIS LAI (the partial correlation coefficient $-0.42, \mathrm{p}=0.29$ for yearly values), which is in line with the in-situ measurement-based knowledge.

The performance of AMSR-E SM products varies with region. Though some previous studies have shown that the JAXA and NASA algorithms can achieve relatively favorable results in Mongolia (Kaihotsu et al., 2009) and the United States (Jackson et al., 2010) respectively, they cannot provide accurate soil moisture estimation in the Tibetan Plateau (Zeng et al., 2015) - consistent with our study of the Loess Plateau. We believe this is because the parameters/coefficients in the retrieval algorithms, which exert an important role in the deviation on soil moisture products, are calibrated in specific regions and should not be extrapolated to other regions. The NASA algorithm is a global empirical regression algorithm, yet some key coefficients in the algorithm are calibrated against data which is mainly from the United States. The JAXA algorithm calibrated the surface roughness and some vegetation parameters using data from Mongolia. As for LPRM, the ground measurements that were used to establish the empirical model are mainly from the United States and some European countries (Holmes et al., 2009; Mladenova et al., 2014). According to our evaluation, the JAXA product performs quite well in estimating the spatiotemporal soil moisture change in the Loess Plateau. This performance is probably because the JAXA algorithm is calibrated with data from an Asian area, with similar soil and climatic conditions to the Loess Plateau. Moreover, vegetation optical depth in the JAXA algorithm is linearly related to vegetation water content which can be determined by the vegetation condition from optical data, thus resulting in the close relationship between JAXA SM and MODIS LAI. In general, our work suggests that the parameters/coefficients of satellite SM algorithms should be recalibrated before the application in a particular region.

Our study divided the Loess Plateau into five zones according to the spatially-varying response of JAXA SM to re-vegetation (Table 1). Revegetation plays the dominant role and thus corresponds to significant decrease of AMSR-E SM in Zone 2, and a slight decrease of AMSR-E SM in Zone3, where both re-vegetation and precipitation are factors impacting change in SM. No change of AMSR-E SM was detected in Zone 5 because the effect of re-vegetation in reducing AMSR-E SM is covered by that of local precipitation. The annual precipitation ranges are $450-550 \mathrm{~mm}, 400-450 \mathrm{~mm}$ and $300-400 \mathrm{~mm}$ for Zones 2,3 and 4 respectively. The zonal difference agrees with the conclusion based on the in-situ measurements; namely, that re-vegetation has the largest 
Table 1

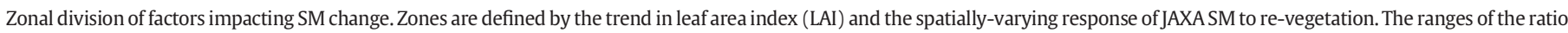
of annual potential evaporation (PET) to annual precipitation (PPT), and annual precipitation are also shown for each zone.

\begin{tabular}{|c|c|c|c|c|c|}
\hline Zones & Trend of MODIS LAI & Trend of JAXA SM (change rate, $\mathrm{m}^{3} \mathrm{~m}^{-3} \mathrm{yr}^{-1}$ ) & Factors impacting SM change & PET/PPT range & PPT range $\left(\mathrm{mm} \mathrm{yr}^{-1}\right)$ \\
\hline Zone 1 & - & $\downarrow($ trend of $-0.00242, \mathrm{p}=0.015)$ & PPT & $0.9-1.5$ & $>550$ \\
\hline Zone 2 & $\uparrow$ & $\downarrow($ trend of $-0.00172, p=0.019)$ & LAI & $1.0-1.5$ & $450-550$ \\
\hline Zone 3 & $\uparrow$ & $\downarrow($ trend of $-0.00129, p=0.03)$ & LAI, PPT & $1.2-1.7$ & $400-450$ \\
\hline Zone 4 & $\uparrow$ & $\begin{array}{l}-(p=0.32) \\
-\end{array}$ & PPT & $1.5-2.0$ & $300-400$ \\
\hline Zone 5 & - & - & & $>1.5$ & $<300$ \\
\hline
\end{tabular}

negative impact on soil moisture at sites that receive $<600 \mathrm{~mm}$ of annual precipitation (Deng et al., 2016). In areas where the mean annual precipitation was $<400 \mathrm{~mm}$, the $\mathrm{SM}$ was near the wilting point $(\mathrm{SM}=5 \%)$ (Jin et al., 2011). Insufficient SM in these areas fails to support the growth of the new planting, in particular for trees and shrubs. A decline in plant condition when SM is depleted is widely observed in the Loess Plateau. The planted trees were found to have reduced stature and a shrub-like in appearance in places where precipitation is $<500 \mathrm{~mm} \mathrm{yr}^{-1}$ (Hou et al., 1991; McVicar et al., 2010).

\subsection{Implication for re-vegetating dryland regions}

Our analysis using JAXA retrievals discovered that the increase of land cover in the Loess Plateau comes at the cost of overconsumption of soil water. This finding is in line with the local opinion that the revegetation policy, which did not consider the amount of soil water available, is characterized by over-planting. Moreover, our study found that the soil water consumption of over-planted landscapes relies heavily on the local precipitation. The overconsumption of soil water mainly occurred in areas with annual precipitation in the range $470-550 \mathrm{~mm}$ (e.g., zone II in Table 1). This rainfall band is a transition area with the ecosystem composed of forest and shrubland. Interestingly, the overconsumption of soil water supports a most significant increase in plant cover (Fig. 4) and an enhancement of ecosystem services in this area (see carbon sequestration in X. M. Feng et al., (2013) and Q. Feng et al., (2013), soil conservation in Fu et al., 2011). However, the increases of plant cover and ecosystem service come at the cost of sustainability of plant growth, causing poor growth and shrub-like malformations of the trees that were planted (Cao, 2008), although overconsumption of soil water in the growing season was partially off-set by recharge of the soil water reservoir in the non-growing season (compare Fig. 4b and c). This effect occurs particularly in areas of mean annual precipitation in the range $400-450 \mathrm{~mm}$ (zone III in Table 1). For example, Jian et al. (2014) report a negative change in SM in every month of the growing season. According to Jian et al. (2014), SM approaches the wilting point at the end of the growing season; it then recovers during the non-growing season. Also, overuse of soil water was partially off-set by extra recharge in particularly wet years (Seneviratne et al., 2010) (zone IV in Table 1). We therefore conclude that planting in semi-arid areas should pay special attention to the local precipitation. In areas with low annual precipitation $(<470 \mathrm{~mm})$, the over-plantation will not be supported by the water (Jin et al., 2011). However, planting will increase soil water in wetter areas (annual precipitation $>550 \mathrm{~mm}$ ) by improving the soil water-holding capacity. However, in transition areas with annual precipitation in the range 450-550 mm, planners should consider the appropriate plant density and plant appropriate xerophytes species to avoid over-planting destroying the water balance. Furthermore, since the response of SM to re-vegetation is influenced by climate change, the reported warming and drying climatic trends in the Loess Plateau are likely to put extra stress on the water demands of the planted vegetation (Yun et al., 2011; Sun et al., 2015). Studies of the vegetation capacity of the Loess Plateau should pay attention not only to the total amount, but also to the seasonal distribution of annual precipitation: the distribution between the growing season and the non-growing season, and the variation between dry years and wet years.

\subsection{Implication for evaluation and appliance of satellite SM retrieval}

The accuracy required of AMSR-E retrievals remains in debate. For example, Tuttle and Salvucci (2014) deemed that LPRM products are useful in more rugged regions. However, Chen et al. (2013) declared that JAXA SM is capable of reflecting the soil moisture dynamics with a small bias, particularly in semi-arid regions. Our study concluded that JAXA SM is the best among AMSR-E retrievals in reflecting the insitu based knowledge that soil moisture has decreased as a result of the massive re-vegetation in the water-limited Loess Plateau. Moreover, taking advantage of time series of satellite monitoring data covering the same region at frequent intervals (one day in this study), our work presents a different conclusion compared to the one drawn from model simulation, where Shawn et al. (2016) concluded that soil moisture decrease due to massive re-vegetation would be greater in drier areas. A likely reason is that the model failed to simulate the interaction between soil moisture and plant growth, thus exaggerating the plant growth, and hence the soil water consumption, in arid areas. Currently there is much interest in addressing the dynamics of the Earth system by combining in-situ measurements, satellite observations and a modeling approach (Feng et al., 2016); AMSR-E retrievals of soil moisture should aid this line of research by acting as a data source for identifying the location and spatial extent, of areas where soil moisture is sensitive to climate change and managed re-vegetation, although currently the data does not meet the accuracy needed for precise evaluation.

\section{Conclusions}

Our study proposes a new method of evaluation of AMSR-E SM. Although developed for the Loess Plateau, it should be applicable to other regions without a soil moisture monitoring network. We conclude that currently available soil moisture products from satellite observation are not sufficient skillful for the application of instantaneous absolute values. However, JAXA AMSR-E retrievals did capture the soil moisture decrease following the massive re-vegetation of the Loess Plateau. Furthermore, we found soil moisture decrease in response to the massive re-vegetation occurred over the transition zone of grassforest ecosystems with annual precipitation between 470 and $550 \mathrm{~mm}$. Satellite SM gives an essential alternative to field measurement and model simulation; it draws a general picture of the response of soil moisture to re-vegetation at the regional scale.

\section{Acknowledgment}

This work was funded by the National Natural Science Foundation of China (No. 41390464 and 41561134016), CAS-CSIRO Cooperative Research Program (Grant No. GJHZ1502) and the Major Program of High Resolution Earth Observation System (30-Y30B13-9003-14/1602).The authors also wish to thank the anonymous reviewers for their valuable and useful suggestions that resulted in substantial improvements to this paper. 


\section{References}

Adams, J.R., McNairn, H., Berg, A.A., Champagne, C., 2015. Evaluation of near-surface soil moisture data from an AAFC monitoring network in Manitoba, Canada: implications for L-band satellite validation. J. Hydrol. 521, 582-592.

Al Bitar, A., Leroux, D., Kerr, Y.H., Merlin, O., Richaume, P., Sahoo, A., et al., 2012. Evaluation of SMOS soil moisture products over continental U.S, using the SCAN/SNOTEL net work. IEEE Trans. Geosci. Remote Sens. 50:1572-1586. http://dx.doi.org/10.1109/ TGRS.2012.2186581.

Albergel, C., de Rosnay, P., Gruhier, C., Munoz-Sabater, J., Hasenauer, S., Isaksen, L., et al., 2012. Evaluation of remotely sensed and modelled soil moisture products using global ground-based in-situ observations. Remote Sens. Environ. 118:215-226. http://dx. doi.org/10.1016/j.rse.2011.11.017.

Al-Yaari, A., Wigneron, J.-P., Ducharne, A., Kerr, Y., de Rosnay, P., de Jeu, R., et al., 2014a. Global-scale evaluation of two satellite-based passive microwave soil moisture datasets (SMOS and AMSR-E) with respect to Land Data Assimilation System estimates. Remote Sens. Environ. 149, 181-195.

Al-Yaari, A., Wigneron, J.-P., Ducharne, A., Kerr, Y., Wagner, W., De Lannoy, G., et al., 2014b. Global-scale comparison of passive (SMOS) and active (ASCAT) satellite based microwave soil moisture retrievals with soil moisture simulations (MERRALand). Remote Sens. Environ. 152, 614-626.

Aranda, I., Forner, A., Cuesta, B., Valladares, F., 2012. Species-specific water use by forest tree species: from the tree to the stand. Agric. Water Manag. 114:67-77. http://dx. doi.org/10.1016/j.agwat.2012.06.024.

Bindlish, R., Jackson, T.J., Wood, E., Gao, H., Starks, P., Bosch, D., et al., 2003. Soil moisture estimates from TRMM microwave imager observations over the southern United States. Remote Sens. Environ. 85, 507-515.

Brocca, L., Hasenauer, S., Lacava, T., Melone, F., Moramarco, T., Wagner, W., et al., 2011. Soil moisture estimation through ASCAT and AMSR-E sensors: an intercomparison and validation study across Europe. Remote Sens. Environ. 115, 3390-3408.

Bublinec, E., 1971. Influence of pine forests on instant soil moisture in climatic variable years (in Slovak). J. Hydrol. Hydromech. 19, 622-650 (Bratislava).

Cao, S.X., 2008. Why large-scale afforestation efforts in China have failed to solve the desertification problem. Environ. Sci. Technol. 42, 1826-1831.

Cao, S.X., Chen, L., Shankman, D., Wang, C.M., Wang X.B., Zhang, H., 2011. Excessive reliance on afforestation in China's arid and semi-arid regions: lessons in ecological restoration. Earth Sci. Rev. 104:240-245. http://dx.doi.org/10.1016/j.earscirev.2010.11. 002.

Carlson, T.N., Gillies, R.R., Perry, E.M., 1994. A method to make use of thermal infrared temperature and NDVI measurements to infer surface soil water content and fractional vegetation cover. Remote Sens. Rev. 9, 161-173.

Carlson, T.N., Gillies, R.R., Schmugge, T.J., 1995. An interpretation of methodologies for indirect measurement of soil-water content. Agric. For. Meteorol. 77, 191-205.

Celano, G., Palese, A.M., Ciucci, A., Martorella, E., Vignozzi, N., Xiloyannis, C., 2011. Evaluation of soil water content in tilled and cover-cropped olive orchards by the geoelectrical technique. Geoderma 63, 163-170.

Chauhan, N.S., Miller, S., Ardanuy, P., 2003. Spaceborne soil moisture estimation at high resolution: a microwave-optical/IR synergistic approach. Int. J. Remote Sens. 24 4599-4622.

Cheema, M.J.M., Bastiaanssen, W.G.M., Rutten, M.M., 2011. Validation of surface soil moisture from AMSR-E using auxiliary spatial data in the transboundary Indus Basin. J. Hydrol. 405:137-149. http://dx.doi.org/10.1016/j.jhydrol.2011.05.016.

Chen, L.D., Huang, Z.L., Gong, J., Fu, B.J., Huang, Y.L., 2007. The effect of land cover/vegetation on soil water dynamic in the hilly area of the loess plateau, China. Catena 70: 200-208. http://dx.doi.org/10.1016/j.catena.2006.08.007.

Chen, L.D., Wang, J.P., Wei, W.T., Fu, B.J., Wu, D.P., 2010. Effects of landscape restoration on soil water storage and water use in the Loess Plateau region, China. For. Ecol. Manag. 259:1291-1298. http://dx.doi.org/10.1016/j.foreco.2009.10.025.

Chen, X., Zhang, Z.C., Chen, X.H., Shi, P., 2009. The impact of land use and land cover changes on soil moisture and hydraulic conductivity along the karst hillslopes of southwest China. Environ. Earth Sci. 59:811-820. http://dx.doi.org/10.1007/s12665009-0077-6.

Chen, Y.P., Wang, K.B., Lin, Y.S., Shi, W.Y., Song, Y., He, X.H., 2015. Balancing green and grain trade. Nat. Geosci. 8, 739-741.

Chen, Y.Y., Yang, K., Qin, J., Zhao, L., Tang, W.J., Han, M.L., 2013. Evaluation of AMSR-E retrievals and GLDAS simulations against observations of a soil moisture network on the central Tibetan Plateau. J. Geophys. Res. D: Atmos. 118:4466-4475. http://dx. doi.org/10.1002/jgrd.50301

Dall'Amico, J., Schlenz, F., Loew, A., Mauser, W., 2012. First results of SMOS soil moisture validation in the upper Danube catchment. IEEE Trans. Geosci. Remote Sens. 50: 1507-1516. http://dx.doi.org/10.1109/TGRS.2011.2171496.

Del Lungo, A., Ball, J., Carle, J., 2006. Global planted forests thematic study: results and analysis. Planted Forests and Trees Working Paper. Food and Agriculture Organization of the United Nations, Rome, Italy, pp. 38-42.

Deng, L., Liu, G.B., Shangguan, Z.P., 2014. Land use conversion and changing soil carbon stocks in China's 'Grain-for-Green' program: a synthesis. Glob. Chang. Biol. 20: 3544-3556. http://dx.doi.org/10.1111/gcb.12508.

Deng, L., Yan, W.M., Zhang, Y.W., Shangguan, Z.P., 2016. Severe depletion of soil moisture following land-use changes for cological restoration: evidence from northern China. For. Ecol. Manag. 366:1-10. http://dx.doi.org/10.1016/j. foreco.2016.01.026.

De Ridder, K., 2003. Surface soil moisture monitoring over Europe using Special Sensor Microwave/Imager (SSM/I) imagery. J. Geophys. Res. Atmos. 108 (D14), 4422.

Dorigo, W.A., Scipal, K., Parinussa, R.M., Liu, Y.Y., Wagner, W., de Jeu, R.A.M., et al., 2010. Error characterisation of global active and passive microwave soil moisture datasets. Hydrol. Earth Syst. Sci. 7, 2605-2616.
Draper, C., Walker, J., Steinle, P., de Jeu, R., Holmes, T., 2009. An evaluation of AMSR-E derived soil moisture over Australia. Remote Sens. Environ. 113:703-710. http://dx.doi. org/10.1016/j.rse.2008.11.011.

Entekhabi, D., Njoku, E.G., O'Neill, P.E., Kellogg, K.H., Crow, W.T., Edelstein, W.N., et al., 2010. The soil moisture active and passive (SMAP) mission. Proc. IEEE 98, 704-716.

Entekhabi, D., Reichle, R.H., Koster, R.D., Crow, W.T., 2009. Performance metrices for soil moisture retrievals and application requirements. J. Hydrometeorol. 11, 832-840.

Escorihuela, M.J., Quintana-Seguí, P., 2016. Comparison of remote sensing and simulated soil moisture datasets in Mediterranean landscapes. Remote Sens. Environ. 180, 99-114.

Famiglietti, J.S., Devereaux, J.A., Laymon, C.A., Tsegaye, T., Houser, P.R., Jackson, T.J., et al., 1999. Ground-based investigation of soil moisture variability within remote sensing footprints during the Southern Great Plains 1997 (SGP97) hydrology experiment. Water Resour. Res. 35, 1839-1851.

Feng, X.M., Sun, G., Fu, B.J., Su, C.H., Liu, Y., Lamparski, H., 2012. Regional effects of vegetation restoration on water yield across the Loess Plateau, China. Hydrol. Earth Syst. Sci. 16:2617-2628. http://dx.doi.org/10.5194/hess-16-2617-2012.

Feng, X.M., Fu, B.J., Lu, N., Zeng, Y., Wu, B.F., 2013a. How ecological restoration alters ecosystem services: an analysis of carbon sequestration in China's Loess Plateau. Sci. Report. (I):2846 http://dx.doi.org/10.1038/srep02846.

Feng, X.M., Fu, B.J., Piao, S.L., Wang, S., Ciais, P., Zeng, Z.Z., et al., 2016. Revegetation in China's Loess Plateau is approaching sustainable water resource limits. Nat. Clim. Chang. 6:1019-1022. http://dx.doi.org/10.1038/nclimate3092.

Feng, Q., Zhao, W.W., Oiu, Y., Zhao, M.Y., Zhong, L., 2013b. Spatial heterogeneity of soil moisture and the scale variability of its influence factors: a case study in the Loess Plateau. Water 5:1226-1242. http://dx.doi.org/10.3390/w5031226.

Fu, B.J., Liu, Y., Lü, Y.H., He, C.S., Zeng, Y., Wu, B.F., 2011. Assessing the soil erosion control service of ecosystems change in the Loess Plateau of China. Ecol. Complex. 8: 284-293. http://dx.doi.org/10.1016/j.ecocom.2011.07.003.

Gillies, R.R., Carlson, T.N., 1995. Thermal remote sensing of surface soil water content with partial vegetation cover for incorporation into climate models. J. Appl. Meteorol. 34, $745-756$

Gillies, R.R., Carlson, T.N., Cui, J., Kustas, W.P., Humes, K.S., 1997. A verification of the 'triangle' method for obtaining surface soil water content and energy fluxes from remote measurements of the normalized difference vegetation index (NDVI) and surface radiant temperature. Int. J. Remote Sens. 18, 3145-3166.

Gruber, A., Dorigo, W.A., Zwieback, S., Xaver, A., Wagner, W., 2013. Characterizing coarsescale representativeness of in situ soil moisture measurements from the International Soil Moisture Network. Vadose Zone J. 12:522-525. http://dx.doi.org/10.2136/ vzj2012.0170

Gruber, A., Su, C.-H., Zwieback, S., Crow, W., Dorigo, W., Wagner, W., 2016. Recent advances in (soil moisture) triple collocation analysis. Int. J. Appl. Earth Obs. Geoinf. 45, 200-211.

Hawley, M.E., Jackson, T.J., McCuen, R.H., 1983. Surface soil moisture variation on small agricultural watersheds. J. Hydrol. 62, 179-200.

Hald, A., 1952. Statistical Theory With Engineering Applications. John Wiley\& Sons, New York, US

Holmes, T.R.H., de Jeu, R.A.M., Owe, M., Dolman, A.J., 2009. Land surface temperature from Ka band $(37 \mathrm{GHz}$ ) passive microwave observations. J. Geophys. Res. Atmos. 114, D04113.

Holzman, M.E., Rivas, R., Piccolo, M.C., 2014. Estimating soil moisture and the relationship with crop yield using surface temperature and vegetation index. Int. J. Appl. Earth Obs. Geoinf. 28, 181-192.

Hou, Q., Huang, X., Han, S., Zhang, X., 1991. Study on the forming of 'small olded tree' and transforming way in the Loess Plateau I. The distribution and growth nature of the small olded tree. J. Soil Water Conserv. 5, 64-72 (In Chinese).

Hutchinson, M.F., 1991. The application of thin plate smoothing splines to continent-wide data assimilation. Data Assimilation Systems. 27, pp. 104-113.

Imaoka, K., Kachi, M., Kasahara, M., Ito, N., Nakagawa, K., Oki, T., 2010. Instrument performance and calibration of AMSR-E and AMSR-2. Int. Arch. Photogramm. Remote. Sens. Spat. Inf. Sci. 38, 13-16.

Im, J., Park, S., Rhee, J., Baik, J., Choi, M., 2016. Downscaling of AMSR-E soil moisture with MODIS products using machine learning approaches. Environ. Earth Sci. 75:1120. http://dx.doi.org/10.1007/s12665-016-5917-6.

IPCC, 2014. Fifth Assessment Report, Climate Change 2014: Synthesis Report. Cambridge University Press, Cambridge, UK

Ivanov, V.Y., Fatichi, S., Jenerete, G.D., Fspeleta, J.F., Troch, P.A., Huxman, T.E., 2010. Hysteresis of soil moisture spatial heterogeneity and the "homogenizing" effect of vegetation. Water Resour. Res. 46, W009521. http://dx.doi.org/10.1029/2009WR008611.

Jackson, T. Bidlish, R., Cosh, M.H., Zhao, T., Starks, P., Bosch, D., et al., 2012. Validation of Soil Moisture and Ocean Salinity (SMOS) soil moisture over watershed networks in the U.S. IEEE Trans. Geosci. Remote Sens. 50, 1530-1543.

Jackson, T.J., Cosh, M.H., Bindlish, R., Starks, P.J., Bosch, D.D., Seyfried, M., et al., 2010. Validation of advanced microwave scanning radiometer soil moisture products. IEEE Trans. Geosci. Remote Sens. 48, 4256-4272.

Jackson, T.J., Schmugge, T.J., Wang, J.R., 1982. Passive microwave sensing of soil moisture under vegetation canopies. Water Resour. Res. 18, 1137-1142.

Jian, S.Q., Zhao, C.Y., Fang, S.M., Yu, K., 2014. Soil water content and water balance simulation of CaraganakorshinskiiKom. In the semiarid Chinese Loess Plateau. J. Hydrol. Hydromech. 62:89-96. http://dx.doi.org/10.2478/johh-2014-0020.

Jiang, L., Islam, S., 1999. A methodology for estimation of surface evapotranspiration over large areas using remote sensing observations. Geophys. Res. Lett. 26, 2773-2776.

Jiang, L., Islam, S., 2001. Estimation of surface evaporation map over southern Great Plains using remote sensing data. Water Resour. Res. 37, 329-340.

Jiang, L., Islam, S., 2003. An intercomparison of regional latent heat flux estimation using remote sensing data. Int. J. Remote Sens. 24, 2221-2236. 
Jin, T.T., Fu, B.J., Liu, G.H., Wang, Z., 2011. Hydrologic feasibility of artificial forestation in the semi-arid Loess Plateau of China. Hydrol. Earth Syst. Sci. 15, 2519-2530.

Jost, G., Schume, H., Hager, H., Markart, G., Kohl, B., 2012. A hillslope scale comparison of tree species influence on soil moisture dynamics and runoff processes during intense rainfall. J. Hydrol. 420-421:112-124. http://dx.doi.org/10.1016/j.jhydrol.2011.11.057.

Kaihotsu, I., Koike, T., Yamanaka, T., Fujii, H., Ohta, T., Tamagawa, K., et al., 2009. Validation of soil moisture estimation by AMSR-E in the Mongolian plateau. J. Remote Sens. Soc. Jpn. 29, 271-281.

Kerr, Y.H., Al-Yaari, A., Rodriguez-Fernandez, N., Parrens, M., Molero, B., Leroux, D., et al., 2016. Overview of SMOS performance in terms of global soil moisture. Remote Sens. Environ. 180, 40-63.

Kerr, Y.H., Waldteufel, P., Wigneron, J.P., Delwart, S., Cabot, F., Boutin, J., et al., 2010. The SMOS mission: new tool for monitoring key elements of the global water cycle. Proc. IEEE 98, 666-687.

Koike, T., Nakamura, Y., Kaihotsu, I., Davva, G., Matsuura, N., Tamagawa, K., Fujii, H., 2004. Development of an advanced microwave scanning radiometer (AMSR-E) algorithm of soil moisture and vegetation water content. Annu. J. Hydraul. Eng. 48, 217-222.

Koike, T., Tsukamoto, T., Kumakura, T., Lu, M., 1996. Spatial and seasonal distribution of surface wetness derived from satellite data. Proceedings of the International Workshop on Macro-scale Hydrological Modeling, pp. 87-96.

Kou, X.Y., Li, C.L., 1985. Some issues on the utility of underground water in Guanzhong plain. Shaanxi Water Resources. 3, pp. 14-19 (in Chinese).

Lal, R., 2001. Potential of desertification control to sequester carbon and mitigate the greenhouse effect. Clim. Chang. 51, 35-72.

Lal, R., 2004. Carbon sequestration in dryland ecosystems. Environ. Manag. 33, 528-544.

Lambin, E.G., Ehrlich, D., 1996. The surface temperature-vegetation index space for land cover and land-cover change analysis. Int. J. Remote Sens. 17, 463-487.

Li, L., Njoku, E.G., Im, E., Chang, P.S., Germain, K.St., 2004. A preliminary survey of radiofrequency interference over the U.S. in aqua AMSR-E data. IEEE Trans. Geosci. Remote Sens. 42, 380-390

Li, P., Wei, X.M., Jiang, Y.N., Feng, D.P., 2014. Response of groundwater cycle to environmental changes in Guanzhong plain irrigation district. Transactions of the Chinese Society of Agricultural Engineering. 30, pp. 123-131 (in Chinese).

Liu, J.G., Li, S.X., Ouyang, Z.Y., Tam, C., Chen, X.D., 2008. Ecological and socioeconomic effects of China's policies for ecosystem service. Proc. Natl. Acad. Sci. U. S. A. 28 (105): 9477-9482. http://dx.doi.org/10.1073/pnas.0706436105.

Lü, Y., Fu, B.J., Feng, X.M., Zeng, Y., Liu, Y., Chang, R.Y., et al., 2012. A policy-driven large scale ecological restoration: quantifying ecosystem services changes in the Loess Plateau of China. PLoS ONE 7, e31782. http://dx.doi.org/10.1371/journal.pone.0031782.

McVicar, T.R., Van Niel, T.G., Li, L.T., Wen, Z.M., Yang, Q.K., Li, R., et al., 2010. Parsimoniously modeling perennial vegetation suitability and identifying priority areas to support China's re-vegetation program in the Loess Plateau: matching model complexity to data availability. For. Ecol. Manag. 259, 1277-1290.

Meesters, A.G.C.A., de Jeu, R.A.M., Owe, M., 2005. Analytical derivation of the vegetation optical depth from the microwave polarization difference index. IEEE Geosci. Remote Sens. Lett. 2, 121-123.

Menz, M.H.M., Dixon, K.W., Hobbs, R.J., 2013. Hurdles and opportunities for landscapescale restoration. Science 339, 526-527.

Mialon, A., Coret, L., Kerr, Y.H., Secherre, F., Wigneron, J.P., 2008. Flagging the topographic impact on the SMOS signal. IEEE Trans. Geosci. Remote Sens. 46, 689-694.

Miralles, D.G., Crow, W.T., Cosh, M.H., 2010. Estimating spatial sampling errors in coarsescale soil moisture estimates derived from point-scale observations. J. Hydrometeorol. 11, 1423-1429.

Mladenova, I.E., Jackson, T.J., Njoku, E., Bindlish, R., Chan, S., Cosh, M.H., et al., 2014. Remote monitoring of soil moisture using passive microwave-based techniques-theoretical basis and overview of selected algorithms for AMSR-E. Remote Sens. Environ. 144, 197-213.

Mo, T., Choudhury, B.J., Schmugge, T.J., Wang, J.R., Jackson, T.J., 1982. A model for microwave emission from vegetation-covered fields. J. Geophys. Res. Oceans 87 (C13), 11229-11237.

Njoku, E., Chan, S., 2006. Vegetation and surface roughness effects on AMSR-E land observations. Remote Sens. Environ. 100:190-199. http://dx.doi.org/10.1016/j.rse.2005.10. 017.

Njoku, E.G., Entekhabi, D., 1996. Passive microwave remote sensing of soil moisture. J. Hydrol. 184, 101-129.

Njoku, E.G., Jackson, T.J., Lakshmi, V., Chan, T.K., Nghiem, S.V., 2003. Soil moisture retrieval from AMSR-E. IEEE Trans. Geosci. Remote Sens. 41, 215-229.

Njoku, E.G., Li, L., 1999. Retrieval of land surface parameters using passive microwave measurements at 6-18 GHz. IEEE Trans. Geosci. Remote Sens. 37, 79-93.

Owe, M., de Jeu, R., Holmes, T., 2008. Multisensor historical climatology of satellitederived global land surface moisture. J. Geophys. Res. Earth Surf. 113 (F1):196-199. http://dx.doi.org/10.1029/2007JF000769.

Owen, T.W., Carlson, T.N., Gillies, R.R., 1998. An assessment of satellite remotely-sensed land cover parameters in quantitatively describing the climatic effect of urbanization. Int. J. Remote Sens. 19, 1663-1681.

Peng, J., Niesel, J., Loew, A., Zhang, S.Q., Wang, J., 2015. Evaluation of satellite and reanalysis soil moisture products over southwest China using ground-based measurements. Remote Sens. 7:15729-15747. http://dx.doi.org/10.3390/rs71115729.

Piles, M., Camps, A., Vall-Llossera, M., Corbella, I., Panciera, R., Rudiger, C., et al., 2011. Downscaling SMOS-derived soil moisture using MODIS visible/infrared data. IEEE Trans. Geosci. Remote Sens. 49, 3156-3166.

Price, J.C., 1990. Using spatial context in satellite data to infer regional scale evapotranspiration. IEEE Trans. Geosci. Remote Sens. 28, 940-948.

Qin, J., Yang, K., Lu, N., Chen, Y.Y., Zhao, L., Han, M.L., 2013. Spatial upscaling of in-situ soil moisture measurements based on MODIS-derived apparent thermal inertia. Remote Sens. Environ. 138, 1-9.
Rosnay, P.D., Calvet, J.C., Kerr, Y., Wigneron, J.P., Lemaître, F., Escorihuela, M.J., et al., 2006 SMOSREX: a long term field campaign experiment for soil moisture and land surface processes remote sensing. Remote Sens. Environ. 102:377-389. http://dx.doi.org/10. 1016/j.rse.2006.02.021.

Rötzer, K., Montzka, C., Bogena, H., Wagner, W., Kerr, Y.H., Kidd, R., et al., 2014. Catchment scale validation of SMOS and ASCAT soil moisture products using hydrological modeling and temporal stability analysis. J. Hydrol. 519, 934-946.

Sanchez-Mejia, Z., Papuga, S., Swetish, J., Leeuwen, W., Szutu, D., Hartfield, K., 2014. Quantifying the influence of deep soil moisture on ecosystem albedo: the role of vegetation. Water Resour. Res. 50:4038-4053. http://dx.doi.org/10.1002/2013WR014150.

Sánchez-Ruiz, S., Piles, M., Sánchez, N., Martínez-Fernández, J., Vall-llossera, M., Camps, A 2014. Combining SMOS with visible and near/shortwave/thermal infrared satellite data for high resolution soil moisture estimates. J. Hydrol. 516, 273-283.

Sandholt, I., Rasmussen, K., Andersen, J., 2002. A simple interpretation of the surface temperature/vegetation index space for assessment of surface moisture status. Remote Sens. Environ. 79, 213-224.

Schmugge, T., 1978. Remote sensing of surface soil moisture. J. Appl. Meteorol. 17, 1549-1557.

Seneviratne, S.I., Corti, T., Davin, E.L., Hirschi, M., Jaeger, E.B., Lehner, I., et al., 2010. Investigating soil moisture-climate interactions in a changing climate: a review. Earth Sci. Rev. 99:125-161. http://dx.doi.org/10.1016/j.earscirev.2010.02.004.

Shawn, W.S., Richard, O.S., Robert, M.B., Patrick, H.M., Eugene, F.K., 2016. A long-term analysis of the historical dry boundary for the Great Plains of North America: implications of climatic variability and climatic change on temporal and spatial patterns in soil moisture. Geoderma 274:104-113. http://dx.doi.org/10.1016/j.geoderma. 2016.03.020.

Su, C.H., Ryu, D., Young, R.I., Western, A.W., Wagner, W., 2013. Inter-comparison of microwave satellite soil moisture retrievals over the Murrumbidgee Basin, southeast Australia. Remote Sens. Environ. 134, 1-11.

Su, C.H., Zhang, J., Gruber, A., Parinussa, R., Ryu, D., Crow, W.T., et al., 2016. Error decomposition of nine passive and active microwave satellite soil moisture data sets over Australia. Remote Sens. Environ. 182, 128-140.

Sun, F.X., Lu, Y.H., Fu, B.J., Ma, Z.M., Yao, X.L., 2014. Spatial explicit soil moisture analysis: pattern and its stability at small catchment scale in the loess hilly region of China. Hydrol. Process. 28:4091-4109. http://dx.doi.org/10.1002/hyp.9940.

Sun, W.Y., Song, X.Y., Mu, X.M., Gao, P., Wang, F., 2015. Spatiotemporal vegetation cover variations associated with climate change and ecological restoration in the Loess Plateau. Agric. For. Meteorol. 209:87-99. http://dx.doi.org/10.1016/j.agrformet.2015.05 002.

Tuttle, S.E., Salvucci, G.D., 2014. A new approach for validating satellite estimates of soil moisture using large-scale precipitation: comparing AMSR-E products. Remote Sens. Environ. 142:207-222. http://dx.doi.org/10.1016/j.rse.2013.12.002.

Vivoni, E.R., Rinehart, A.J., Méndez-Barroso, L.A., Aragón, C.A., Bisht, G., Cardenas, M.B., et al., 2008. Vegetation controls on soil moisture distribution in the Valles Caldera, New Mexico, during the North American monsoon. Ecohydrology 1:225-238. http://dx. doi.org/10.1002/eco.11.

Wagner, W., Hahn, S., Kidd, R., Melzer, T., Bartalis, Z., Hasenauer, S., et al., 2013. The ascat soil moisture product: a review of its specifications, validation results, and emerging applications. Meteorol. Z. 22, 5-33.

Wang, H., Li, X.B., Long, H.L., Xu, X., Bao, Y., 2010a. Monitoring the effects of land use and cover type changes on soil moisture using remote-sensing data: a case study in China's Yongding River basin. Catena 82:135-145. http://dx.doi.org/10.1016/j. catena.2010.05.008.

Wang, J.R., 1985. Effect of vegetation on soil moisture sensing observed from orbiting microwave radiometers. Remote Sens. Environ. 17, 141-151.

Wang, S., Fu, B.J., Piao, S.L., Lü, Y.H., Philippe, C., Feng, X.M., et al., 2016. Reduced sediment transport in the Yellow River due to anthropogenic changes. Nat. Geosci. 9, 38-41.

Wang, Y.Q., Shao, M.A., Liu, Z.P., 2010b. Large-scale spatial variability of dried soil layers and related factors across the entire Loess Plateau of China. Geoderma 159:99-108. http://dx.doi.org/10.1016/j.geoderma.2010.07.001.

Wang, Z.Q., Liu, B.Y., Zhang, Y., 2009. Soil moisture of different vegetation types on the Loess Plateau. J. Geogr. Sci. 19:707-718. http://dx.doi.org/10.1007/s11442-009-0707-7.

Western, A.W., Blöschl, G., 1999. On the spatial scaling of soil moisture. J. Hydrol. 217 203-224.

Yang, L., Wei, W., Chen, L.D., Chen, W.L., Wang, J.J., 2014. Response of temporal variation of soil moisture to vegetation restoration in semi-arid Loess Plateau, China. Catena 115:123-133. http://dx.doi.org/10.1016/j.catena.2013.12.005.

Yang, L., Chen, L.D., Wei, W., 2015. Effects of vegetation restoration on the spatial distribution of soil moisture at the hillslope scale in semi-arid regions. Catena 124:138-146. http://dx.doi.org/10.1016/j.catena.2014.09.014.

Yun, L., Gao, L.B., Bi, H.X., Zhu, Q.K., Wang, X.Y., 2011. Spatio-temporal dynamics of soil moisture in silvopastoral system in the Loess Plateau of weat Shanxi province. Procedia Environ. Sci. 8:153-160. http://dx.doi.org/10.1016/j.proenv.2011.10.025.

Yuan, N.M., Fu, Z.T., Zhang, H., Piao, L., Xoplaki, E., Luterbacher, J., 2015. Detrended partialcross-correlation analysis: a new method for analyzing correlations in complex system. Sci. Report. 5:8143. http://dx.doi.org/10.1038/srep08143.

Zeng, J.Y., Chen, K.S., Bi, H.Y., Chen, Q., 2016. A preliminary evaluation of the SMAP radiometer soil moisture product over United States and Europe using ground-based measurements. IEEE Trans. Geosci. Remote Sens. 54, 4929-4940.

Zeng, J.Y., Li, Z., Chen, Q., Bi, H.Y., Qiu, J.X., Zou, P.F., 2015. Evaluation of remotely sensed and reanalysis soil moisture products over the Tibetan Plateau using in-situ observations. Remote Sens. Environ. 163, 91-110.

Zhou, S.T., Miller, A.J., Hood, L.L., 2000. A partial correlation analysis of the stratospheric ozone response to 27-day solar UV variations with temperature effect removed. J. Geophys. Res. Atmos. 105 (D4), 4491-4500. 